\title{
Design and Development of a Constant Current Constant Voltage Fast Battery Charger for Electric Vehicles
}

\author{
Abdulkarim Nasir, Mostafa S. Hamad and Ahmed K. Elshenawy \\ Department of Electrical Engineering Arab Academy for Science and Technology and Maritime Transport, \\ Alexandria, Egypt
}

\begin{abstract}
The issue of zero-emission mobility is one of the most topical, the electric vehicle market being in a continuous growth, which led to the development of new charging technologies. Unfortunately, limiting the autonomy of vehicles is a major problem, which can be solved, in a first phase, by developing fast charging technologies and developing an adequate infrastructure to serve the end user. This article comes in support of those mentioned, highlighting the limitations of the existing methods and proposing the design and development of a closed-loop DC-DC buck converter based battery charger for charging a plug-in electric vehicle using the constant-current and constant-voltage (CCCV) charging scheme. The motivation that led to the approach of this topic is presented in the introductory part, with emphasis on the extreme phenomena resulting from global warming, with direct involvement of the factors that lead to the burning and consumption of fossil fuels. The second chapter, very detailed and comprehensive, is dedicated to Three-phase Controlled Rectifier, starting with topologies, deepening the mathematical model, adopting the Voltage Oriented Control (VOC) strategy to control the three phase rectifier based on high performance direct-quadrature- coordinate controllers, ending with overall rectifier simulation, using MatLAB Simulink. The third chapter actually presents the simulation part, with emphasis on the related diagrams, presentation of parameters, highlighting the battery charge controller for CCCV charging and presentation of the final results. The final part is dedicated to the practical application itself, comprehensive and clear, as well as the whole work.
\end{abstract}

Keywords: battery charger; buck converter; electric vehicle; fast charging; three-phase rectifier

\section{Introduction}

Climate change involves several dimensions and it is one among the foremost complex issues facing the world today [1]. It affects all regions around the world. Ice shields at the poles are melting and the sea-level is rising; as a result of which many regions of the world are experiencing extreme weather events like floods, hurricanes, rainfall shifting, extreme heat-waves, droughts and the likes. As climate change worsens with time, the mentioned dangerous weather events are becoming more frequent and severe. These consequences if not addressed, are expected to intensify in the near decades.

The burning of fossil fuels for electricity, heat or transport is the main source of the heattrapping greenhouse gases like carbon dioxide $(\mathrm{CO} 2)$ which lingers in the atmosphere and 


\section{$4^{\text {th }}$ International Conference on Modern Research in Science, Engineering and Technology}

results in severe change in climate [2]. Amid the growing concerns about the global climate change and the need to mitigate the more frequent and intense negative consequences of it like storms, heat waves, drought, warming oceans, rising sea levels, and melting glaciers that are directly harming animals, destroying the ecosystems they live, and wreak havoc on people's communities and livelihoods, humanity is involved in reducing the flow of these heat-trapping greenhouse gases, either by reducing the burning of fossil fuels or enhancing oceans, forests and soil which are the sinks that accumulate these gases. Moving away from petroleum as the main energy source for powering our transportation is one way to mitigate the climate change. The world is now pursuing transportation systems powered by electricity that can help us scale back the consumption of petroleum.

The process is quite simple as battery electric vehicles (EVs) would be plugged into the grid, and their on-board battery systems will be recharged using clean, renewable electricity. Undoubtedly, electric cars will definitely be more appealing in a world where reducing carbon emissions and pollution is a growing concern. Several researches conducted by experts have shown that electric cars are better for our environment [3]. Even after the production of electric vehicle and the generation of the electricity required to fuel it is considered, EV still emits less greenhouse gases and air pollutants over its life than a petrol or diesel car.

This article aims at developing fast battery charger for EVs which will help cities develop more sustainable transport by reducing the use of fossil fuels and hence saving the environment. The lack of a charging system that can easily and seamlessly recharge EV batteries remains a major step-back to the widespread adoption of electric vehicles. As a result, an EV charging infrastructure that will parallel the existing gasoline stations is critical. However, developing and deploying such an EV charging infrastructure is difficult, and must take into consideration competing industry standards, available technologies, grid impacts, and other technical and policy issues.

Let us first review the state-of-the-art EV charging infrastructure by reviewing the power electronics converter topologies suitable for fast battery chargers specifically focusing on the AC/DC front-end stage design and isolated and non-isolated DC/DC converter topologies and their limitations and why the proposed dc-dc buck converter based battery charging system.

Normally, two different charging approaches are used, namely conductive and inductive charging.

Conductive chargers have hard-wired connection between the power supply and power electronic interfaces (PEI) to do the charging and conventionally consist of a power factor correction (PFC) ac/dc rectifier followed by a dc/dc converter. On the other hand, inductive charging or contactless charging does not use wired connection between the supply and the PEI for charging.

Conductive plug-in Electric Vehicle (PEV) chargers can be classified on the basis of their power level. Currently supported power levels are ac level 1 (L1, $1.92 \mathrm{~kW}$ max), ac level 2 (L2, $19.2 \mathrm{~kW}$ max), and dc level 3 (L3, greater than $19.2 \mathrm{~kW}$ ) [4]. Depending on where the charger resides, conductive PEV chargers can be classified as on-board or off-board. The onboard PEI charger sits inside the PEV and usually consists of two power stages: 1) rectification of ac mains and 2) battery current regulation. This charger type is also referred to as two-stage on-board charger. Off-board chargers are typically fast, high power dc charging solutions (L3 and $20 \mathrm{~kW}$ or more), where the PEI for charging is installed on an external charging infrastructure. 
Inductive or wireless charging techniques use primary (transmitter) and secondary (receiver) coils for transferring power using the principle of magnetic induction. Wireless charging systems commonly have a lower efficiency and power density compared to conductive charging systems [5], [6], [7]. Wireless charging technology review and discussion is beyond the scope of this article.

In the section below, different power electronics converters for fast charging application are identified and compared. Their advantages and disadvantages are discussed. Topology variations and control improvements proposed in literature to better suit fast charging are also discussed. Note that this article does not cover the topologies for on-board chargers. It focuses on the converter topologies suitable for fast charging application only. Reviews of on-board chargers, integrated chargers, and off-board chargers can be found in [8] and [9].

Table 1 summarizes the state-of-the-art dc fast chargers on the market. The state-of-the-art dc fast chargers convert the three-phase ac voltage up to $480 \mathrm{~V}$ to the desired dc voltage by two power electronics conversion stages: an AC/DC rectification stage with power factor correction (PFC), which converts three-phase input ac voltage to an intermediate dc voltage; and a DC/DC stage, which converts the intermediate dc voltage into regulated dc voltage required to charge the electric vehicle. The galvanic isolation between the grid and the EV battery can be provided in one of the two following methods. The first option is to use a linefrequency transformer before the AC/DC stage to provide isolation from the grid (See Fig. 1a). The next DC/DC stage is a non-isolated converter.

TABLE 1: Technical Specifications of state-of-art dc fast chargers

\begin{tabular}{|c|c|c|c|c|c|c|}
\hline $\begin{array}{r}\text { Manufac } \\
\text { turer Model }\end{array}$ & $\begin{array}{r}\text { ABB } \\
\text { Terra 53 }\end{array}$ & $\begin{array}{l}\quad \text { Tritiu } \\
\text { m Veefil- } \\
\text { RT }\end{array}$ & $\begin{array}{l}\quad \text { PHIH } \\
\text { ONG } \\
\text { Integrate } \\
\text { d Type } \\
\end{array}$ & $\begin{array}{l}\quad \text { Tesla } \\
\text { Supercharg } \\
\text { er }\end{array}$ & $\begin{array}{l}\text { EVTEC } \\
\text { espresso\&char } \\
\text { ge }\end{array}$ & $\begin{array}{c}\text { ABB } \\
\text { Terra HP }\end{array}$ \\
\hline Power & $50 \mathrm{~kW}$ & $50 \mathrm{~kW}$ & $\mathrm{~kW}^{120}$ & $135 \mathrm{~kW}$ & $150 \mathrm{~kW}$ & $\mathrm{~kW}^{350}$ \\
\hline $\begin{array}{l}\text { Supporte } \\
\text { d protocols }\end{array}$ & $\begin{array}{c}\text { CCS } \\
\text { Type } 1 \\
\text { CHAd } \\
\text { eMO } 1.0\end{array}$ & $\begin{array}{l}\text { CCS } \\
\text { Type } 1 \& \\
2 \\
\text { CHAd } \\
\text { eMO } 1.0\end{array}$ & $\mathrm{~GB} / \mathrm{T}$ & $\begin{array}{l}\text { Superch } \\
\text { arger }\end{array}$ & $\begin{array}{l}\text { SAE } \\
\text { Combo-1 } \\
\text { CHAdeMO } \\
1.0\end{array}$ & $\begin{array}{c}\text { SAE } \\
\text { Combo-1 } \\
\text { CHAd } \\
\text { eMO } 1.2\end{array}$ \\
\hline $\begin{array}{l}\text { Input } \\
\text { voltage }\end{array}$ & $\begin{array}{l}480 \\
\text { Vac }\end{array}$ & $\begin{array}{c}380- \\
480 \mathrm{Vac} \\
600- \\
900 \mathrm{Vdc}\end{array}$ & $\begin{array}{c}380 \\
\text { Vac } \pm 15 \% \\
480 \\
\text { Vac } \pm 15 \% \\
\end{array}$ & $\begin{array}{l}380-480 \\
\text { Vac }\end{array}$ & $\begin{array}{l}400 \mathrm{Vac} \pm \\
10 \%\end{array}$ & $\begin{array}{l}400 \\
\operatorname{Vac} \\
10 \%\end{array} \quad \pm$ \\
\hline $\begin{array}{l}\text { Output } \\
\text { voltage }\end{array}$ & $\begin{array}{l}200- \\
500 \mathrm{~V} \\
\quad 50-500 \\
\mathrm{~V}^{5}\end{array}$ & $\begin{array}{l}200- \\
500 \mathrm{~V} \\
\quad 50-500 \\
\mathrm{~V}^{5}\end{array}$ & $\begin{array}{l}200- \\
750 \mathrm{~V}\end{array}$ & $\mathrm{~V}^{50-410}$ & $170-500 \mathrm{~V}$ & $\begin{array}{l}150- \\
920 \mathrm{~V}\end{array}$ \\
\hline Output & $120 \mathrm{~A}$ & $125 \mathrm{~A}$ & $240 \mathrm{~A}$ & $330 \mathrm{~A}$ & $300 \mathrm{~A}$ & $375 \mathrm{~A}$ \\
\hline
\end{tabular}


$4^{\text {th }}$ International Conference on Modern Research in

Science, Engineering and Technology

5-7 MARCH 2021

BERLIN, GERMANY

\begin{tabular}{|c|c|c|c|c|c|c|}
\hline current & & & & & & \\
\hline $\begin{array}{c}\text { Peak } \\
\text { efficiency }\end{array}$ & $94 \%$ & $>92 \%$ & $93.5 \%$ & $91 \%$ & $93 \%$ & $95 \%$ \\
\hline Volume & $758 \mathrm{~L}$ & $495 \mathrm{~L}$ & $591 \mathrm{~L}$ & $1047 \mathrm{~L}$ & $1581 \mathrm{~L}$ & $1894 \mathrm{~L}$ \\
\hline Weight & $400 \mathrm{~kg}$ & $165 \mathrm{~kg}$ & $240 \mathrm{~kg}$ & $600 \mathrm{~kg}$ & $400 \mathrm{~kg}$ & $1340 \mathrm{~kg}$ \\
\hline $\begin{array}{c}\text { Time to } \\
\text { add 200 } \\
\text { miles }\end{array}$ & $72 \mathrm{~min}$ & $72 \mathrm{~min}$ & $30 \mathrm{~min}$ & $27 \mathrm{~min}$ & $24 \mathrm{~min}$ & $10 \mathrm{~min}$ \\
\hline
\end{tabular}

The second option is to use a high-frequency transformer inside an isolated DC/DC converter to provide isolation (See Fig. 1b). If a single-module charger does not meet the power requirement of the dc fast charger system, multiple identical modules are connected in parallel to increase the output power as shown in Fig. 1c and Fig. 1d. An example is the Tesla Supercharger, which is made of 12 paralleled modules [10]. Similar approach is used by most manufacturers listed in Table 1.

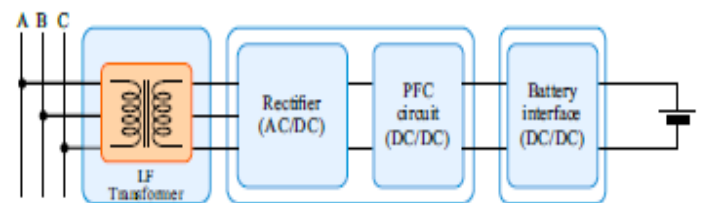

(a) Single-module charger with a non-isolated DCDC converter

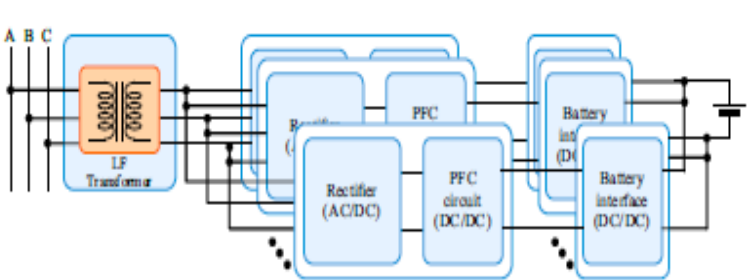

(c) Multiple paralleled modules shown in Fig.la

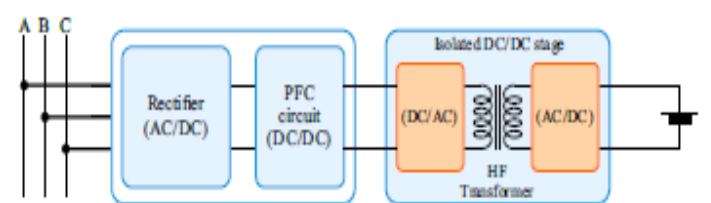

(b) Single-module charger with an isolated DC/DC converter

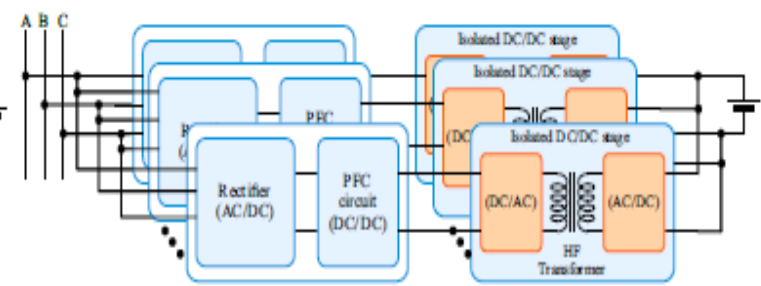

(d) Multiple paralleled modules shown in Fig.lb

Figure 1: Simplified block diagram of conventional dc fast charger power conversion systems

\subsection{Grid-facing AC/DC converters}

Grid-facing AC/DC converters provide an interface between the grid and a regulated dc bus. A key performance requirement for these converters is high power quality on the ac and dc sides, achieved by input current shaping and output voltage regulation [11], [12]. In this article, the AC/DC converters suitable for fast charging are identified and shown in Fig. 2. Their features are summarized in Table 2. They are further categorized as bidirectional and unidirectional converters. 


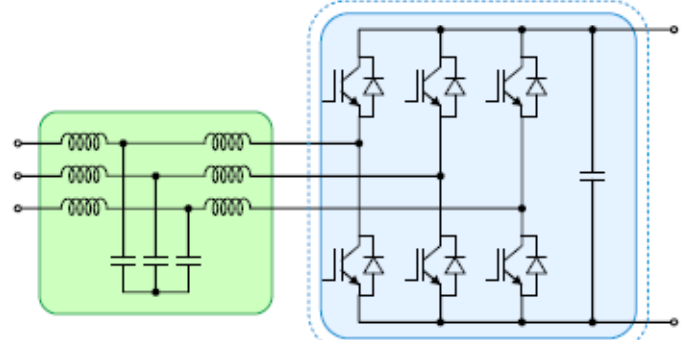

(a) Three-phase PWM rectifier

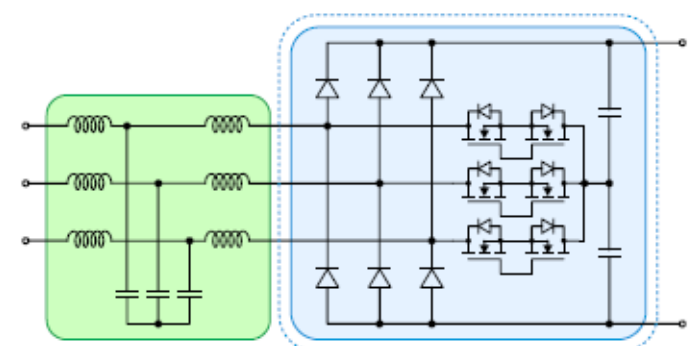

(c) Vienna rectifier

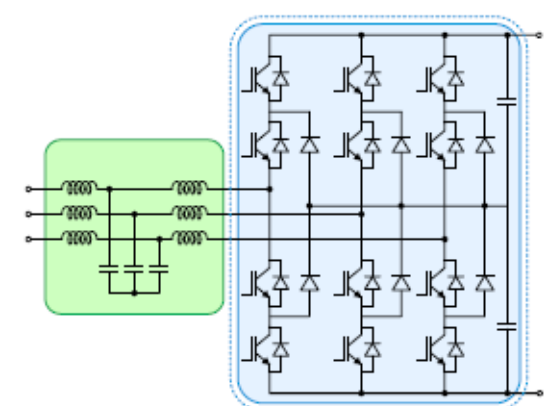

(b) Neutral-point-clamped rectifier

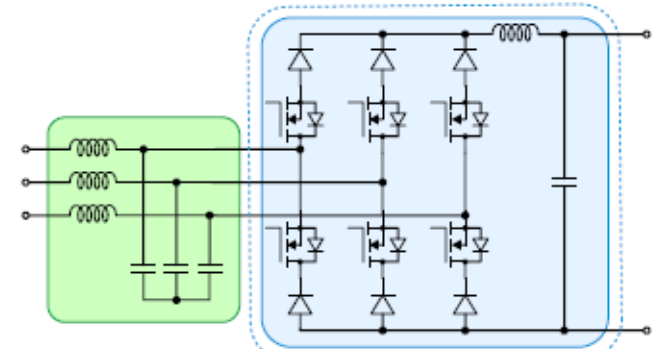

(d) Buck-type rectifier

Figure 2: AC-DC front-end topologies for dc fast chargers

TABLE 2: Comparison of different AC/DC converter topologies for dc fast chargers

\begin{tabular}{|c|c|c|c|c|c|}
\hline Converter & $\begin{array}{c}\text { Switches/Dio } \\
\text { des }\end{array}$ & $\begin{array}{c}\text { Bidirection } \\
\text { al }\end{array}$ & THD & $\begin{array}{c}\text { PF } \\
\text { Range }\end{array}$ & $\begin{array}{c}\text { Control } \\
\text { Complexity }\end{array}$ \\
\hline $\begin{array}{c}\text { PWM } \\
\text { Converter } \\
\text { (Fig. 2a) }\end{array}$ & $6 / 0$ & Yes & Low & Wide & Low \\
\hline $\begin{array}{c}\text { NPC } \\
\text { Converter } \\
\text { (Fig. 2b) }\end{array}$ & $12 / 6$ & Yes & $\begin{array}{c}\text { Very } \\
\text { Low }\end{array}$ & Wide & Moderate \\
\hline $\begin{array}{c}\text { Vienna } \\
\text { (Fig. 2c) }\end{array}$ & $6 / 6$ & No & Very & Limited & Moderate \\
\hline $\begin{array}{c}\text { Buck-type } \\
\text { Converter } \\
\text { (Fig. 2d) }\end{array}$ & $6 / 6$ & Now & Low & Limited & Low \\
\hline
\end{tabular}

\subsubsection{Bidirectional AC/DC converters:}

The most widely used grid-facing AC/DC converter is the three-phase active pulse-widthmodulated (PWM) converter with an LCL filter shown in Fig.2a. This boost-type converter has an output voltage higher than the input line-to-line peak voltage. The six-switch PWM converter generates low harmonic input currents, provides bidirectional power flow, and enables arbitrary power factor $(\mathrm{PF})$ regulation. Due to the simple structure, well established 


\section{$4^{\text {th }}$ International Conference on Modern Research in Science, Engineering and Technology}

5-7 MARCH 2021

BERLIN, GERMANY

control schemes, and the availability of low-cost IGBT devices with sufficient current and voltage ratings, this topology is widely adopted in the state-of-the-art dc fast chargers [13].

Another boost-type converter implementation is the neutral point-clamped (NPC) converter shown in Fig. $2 b$. This three-level converter enables the utilization of devices with lower voltage rating that can provide lower switching losses at an acceptable cost. Moreover, the resulting three-level voltage waveform reduces the input current harmonics and $\mathrm{dv} / \mathrm{dt}$. In [14], a $30 \mathrm{~kW}$ EV charger prototype with an NPC front-end achieves low total harmonic distortion (THD) input current with the leakage inductance of input transformer serving as the ac side filter. Another advantage of using NPC converter as the AC/DC front-end is that it explicitly creates a bipolar dc bus [15]. This property is explored in [16] and [17] to implement an EV charging station with a bipolar dc bus, allowing the DC/DC converters to connect to half of the dc bus voltage. The availability of a bipolar dc bus also provides opportunities for partial-power converter implementation for the DC/DC stage.

\subsubsection{Unidirectional AC/DC converters:}

If only unidirectional power flow is required, the T-type Vienna rectifier, shown in Fig. 2c, is a three-level solution with reduced number of active switches. While it preserves all the advantages of three-level converters, it also shares the common issues of three-level converters including the need for dc-link capacitor voltage balancing. One major limitation for Vienna rectifier is the unidirectional power flow, and limited reactive power control. Due to the restricted modulation vector, the range of achievable reactive power is narrow and depends on the output voltage (the range is $-30^{\circ}<\varnothing<30^{\circ}$ when the output voltage is higher than twice the peak input ac line-to-line voltage, and it is reduced to $\varnothing=0$ if the output voltage is equal to the peak input ac line-to-line voltage). Reference [18] presents a $25 \mathrm{~kW} \mathrm{EV}$ charger prototype with a single-switch Vienna rectifier and four parallel three-level DC/DC. In [19], a $20 \mathrm{~kW}$ SiC-based Vienna rectifier switching at $140 \mathrm{kHz}$ is $98.6 \%$ efficient and features compact passive components. In [20], an EV charger is proposed that uses a Vienna rectifier and two isolated DC/DC converters with each DC/DC converter interfaced to half of the dc bus voltage. By using the DC/DC converters to inject the sixth order harmonic in the dc bus voltage, only one phase of the Vienna rectifier is pulse-width modulated at a time, improving the system efficiency.

If the output voltage is lower than the input line-to-line voltage, a buck-type unidirectional AC/DC converter shown in Fig. $2 d$ can be adopted. This converter has some advantages over the boost-type topologies, such as inherent short-circuit protection, simple inrush current control, and lower output voltage. An additional advantage is that the input current can be controlled in open-loop. The power flow can be reversed only if the output voltage is reversed. Thus, the converter is only unidirectional with fixed output voltage polarity. The achievable phase difference between the input voltage and the input current fundamental depends on the required output voltage. In order to achieve a higher phase difference, the converter needs to operate with a reduced output voltage range (i.e. if the wide output voltage range is required, the phase shift between the input voltage and input current fundamental needs to be kept small). The conduction losses are generally higher than that of the boost-type converter because more devices are connected in series [21], but the switching losses can be lower. The buck-type converter can still operate at very high efficiency, as reported in [22] where $98.8 \%$ efficiency was achieved. In [23], the buck-type rectifier is modified to allow two input phases connecting to each phase leg. With two phase legs conducting the current (in 


\section{$4^{\text {th }}$ International Conference on Modern Research in Science, Engineering and Technology}

5-7 MARCH 2021

BERLIN, GERMANY

contrast to one phase leg for the buck-type rectifier shown in Fig. 2d), the device conduction loss is reduced while maintaining low THD of the input current. Adding a fourth diode bridge leg connected to the midpoint of the diode bridge and the star-point of the input capacitors leads to reduced voltage stress on the switches [24]. This allows the use of switches with lower voltage rating and better performance, potentially achieving higher system efficiency.

\subsection{Isolated DC/DC converters:}

A DC/DC converter after the AC/DC front-end provides an interface to the EV battery. Since the electric vehicle's battery must not be grounded (i.e. it must be floating with respect to the ground) at all times, galvanic isolation is required to maintain the isolation between the grid and the battery so that the battery protection remains unaffected by the charging system. This can be achieved by using an isolated DC/DC converter. Isolated DC/DC converter topologies suitable for EV chargers are presented in Fig. 4; their features are summarized in Table 3. A more comprehensive review of isolated DC/DC converters is provided in [25] and [26].

\subsubsection{Unidirectional isolated DC/DC converters:}

If only unidirectional power flow is required, a possible implementation is the phase-shift full-bridge (PSFB) converter, shown in Fig.3a. When the converter operates in phase-shift PWM control its active switches operate at zero-voltage switching turn-on (ZVS) [27]. The main disadvantages of this topology are the turn-off losses in the active switches, high losses in the output diodes, and the large ringing across the output diodes due to the LCL resonance of the transformer leakage inductance, parasitic capacitance of the reverse biased diodes and the output inductor. To reduce the voltage overshoot and the ringing, active or passive snubber circuits can be applied at the cost of reduced system efficiency. In [28] and [29], a current-fed PSFB converter is proposed by moving the output inductor to the primary side of the transformer and connecting the diode bridge to an output capacitor directly. This approach minimizes the voltage overshoot and the ringing but the ZVS range becomes highly loaddependent. To maintain ZVS over a wide operating range for EV battery charging, trailing edge PWM is used in [28] while auxiliary circuits are proposed in [29].

Another unidirectional isolated DC/DC converter for fast charging is the LLC resonant converter, shown in Fig. 3b. Converter output voltage is regulated by changing the switching frequency to adjust the impedance ratio of resonant tank to equivalent load.

The LLC converter utilizes the magnetizing current to achieve ZVS, resulting in low turnoff losses and low transformer losses [30]. The LLC converter can achieve very high efficiency if the input-to-output voltage ratio is narrow [31]. However, it suffers from limited light-load power regulation capability and the ZVS condition may not hold for a wide operating range, thus negatively impacting efficiency.

Multiple approaches are proposed to improve performance for a wide output voltage range and at light load conditions. Various control methods are proposed including PWM, phaseshift, and other hybrid modulation schemes to narrow the range of operating frequency while broadening the output range [32]. In [33], a variable dc voltage is regulated by the AC/DC converter to match the EV battery voltage, allowing the LLC converter to always operate 


\section{$4^{\text {th }}$ International Conference on Modern Research in Science, Engineering and Technology}

around the resonant frequency with maximum efficiency. Although this method is simple and effective with no extra hardware, wide output voltage range is not guaranteed since the dc voltage variation is limited by the grid voltage and switch voltage rating. Hardware modifications include employing multiple transformers and multiple rectifiers on transformer secondary side. In [34], an extra capacitor paralleled with a four-quadrant switch is inserted in the LLC resonant tank. By modulating the four-quadrant switch, the inserted capacitance and therefore the resonant frequency adapts to the load, improving the efficiency at light-load condition. Despite their effectiveness, these methods require additional hardware and result in higher system cost and larger system volume. Also, a smooth transition between multiple configurations during operation is difficult to achieve.

Another issue for the LLC converter is that the resonant capacitor has to withstand high voltage stress at high power, which complicates component selection. To enhance the power rating and alleviate the stress on switching devices and resonant components, a multilevel LLC converter, a three-phase LLC converter, and an LLC converter with paralleled modules can be used.

\subsubsection{Bidirectional isolated DC/DC converters:}

If bidirectional power flow is required, a dual active bridge (DAB) converter (shown in Fig. 3c) can be used for EV charging applications due to its high power density, high efficiency, buck and boost capability, low device stress, small filter components, and low sensitivity to component variation [35], [36]. When introduced in 1991 [36], the DAB converter was not widely adopted due to the high power losses and relatively low switching frequency of the power semiconductor devices at that time. More recently, the DAB converter started gaining attention, due to the capabilities of the new SiC-and GaN-based power semiconductor devices and the advances in Nano-crystalline and amorphous soft magnetic materials, which enabled the converter efficiency and power density improvements. In the DAB converter, the power flow is controlled by adjusting the phase shift between primary and secondary voltage, with transformer leakage inductance serving as the power transfer element. Owing to its simple structure and ZVS operation, the DAB converter has been extensively used in isolated bidirectional DC/DC conversion applications. 


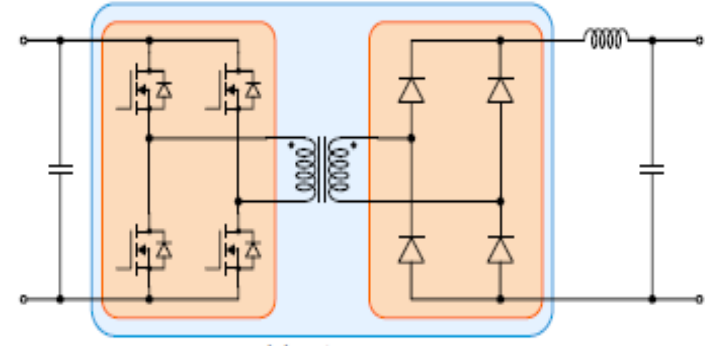

(a) PSFB converter

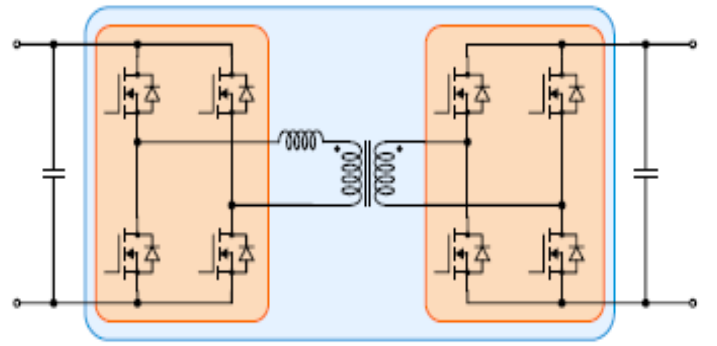

(c) DAB converter

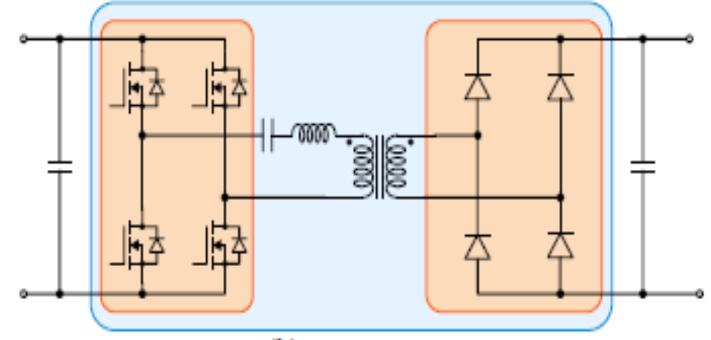

(b) LLC converter

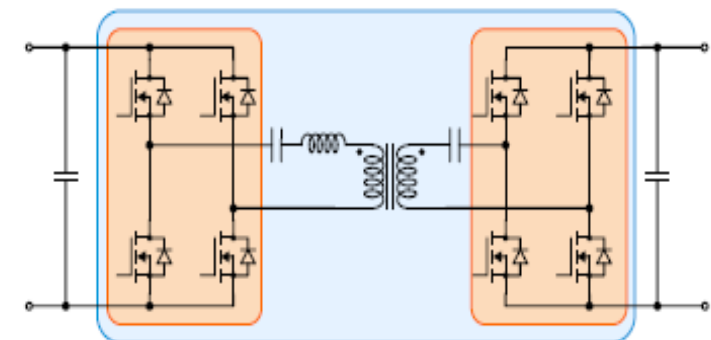

(d) CLLC converter

Figure 3: Isolated DC-DC converter topologies for dc fast chargers

TABLE 3: Comparison of different isolated DC/DC converter topologies for dc fast chargers

\begin{tabular}{|c|c|c|c|}
\hline Converter & $\begin{array}{c}\text { Switches/ } \\
\text { Diodes }\end{array}$ & $\begin{array}{c}\text { Bidirection } \\
\text { al }\end{array}$ & $\begin{array}{c}\text { Major Advantages and } \\
\text { Disadvantages }\end{array}$ \\
\hline $\begin{array}{c}\text { PSFB } \\
\text { converter } \\
\text { (Fig.3a) }\end{array}$ & $4 / 4$ & No & $\begin{array}{c}\text { Simple Control; wide output range. } \\
\text { High switching losses in primary } \\
\text { switches and output diodes; duty-cycle } \\
\text { loss; hard to realize ZVS under light- } \\
\text { load. }\end{array}$ \\
\hline $\begin{array}{c}\text { LLC } \\
\text { (Fig.3b) }\end{array}$ & $4 / 4$ & No & $\begin{array}{c}\text { Low reactive current; ZVS on } \\
\text { primary side and ZCS on secondary } \\
\text { side. }\end{array}$ \\
\hline $\begin{array}{c}\text { DAB } \\
\text { converter } \\
\text { (Fig.3c) }\end{array}$ & $8 / 0$ & Yes & $\begin{array}{c}\text { Limited controllability; hard to } \\
\text { maintain high efficiency and ZVS } \\
\text { under wide operating range. }\end{array}$ \\
\hline $\begin{array}{c}\text { CLLC } \\
\text { converter } \\
\text { (Fig.3d) }\end{array}$ & $8 / 0$ & $\begin{array}{c}\text { Wide achievable output range. } \\
\text { Inherent reactive current; trade-off } \\
\text { between reactive power and ZVS } \\
\text { condition. }\end{array}$ \\
\hline
\end{tabular}




\section{$4^{\text {th }}$ International Conference on Modern Research in Science, Engineering and Technology}

5-7 MARCH 2021

BERLIN, GERMANY

For EV battery charging, the converter is required to operate with a wide range of voltage gain and power due to the EV charging profile, under which reactive power can increase dramatically and ZVS condition no longer holds [37]. This causes a dilemma in the design of leakage inductance, in which high leakage benefits a wide ZVS range but worsens the reactive power and results in lower efficiency, and vice versa [38]. To improve the performance under a wide operating range, various modulation schemes have been proposed. In [39], authors propose dual-phase-shift (DPS) modulation to minimize the current-stress of switching devices, where primary and secondary duty cycle are introduced as an additional degrees of freedom. In [40], the DPS is adopted to achieve ZVS under full load range. In [41], the concept of DPS is further extended to triple-phase-shift (TPS) to enable more degrees of freedom and achieve multiple design objectives such as broader ZVS range, lower current stress, and improved efficiency. In addition, hybrid modulation incorporates operating frequency and pulse density to regulate the transferred power without sacrificing ZVS while controlling the reactive power flow [42]. Recent work in [43] applies TPS to enhance lightload efficiency while switching to DPS to reduce the circulating current under medium- and heavy-load conditions. However, all proposed control strategies have inherent performance trade-offs, and require complex modulation schemes that may be difficult to implement and may not be as robust to parameter variation. Another concern is the high frequency charging ripple resulting from the reactive power that is inherent to DAB converter operation [44].

Another variant of the bidirectional DC/DC converter is the CLLC converter shown in Fig 4d [45]. Due to its symmetrical circuit, the CLLC converter provides the same voltage gain characteristic in both power flow directions, which reduces the control complexity and facilitates power regulation. Moreover, the CLLC converter distributes two resonant capacitors on both sides of the transformer, which helps reduce the resonant capacitor voltage stress compared to the LLC converter. Compared with the DAB converter, the leakage inductance required for the CLLC resonant tank is much smaller. As a result, the reactive power circulating in the converter is also smaller. Further, the sinusoidal resonant current of the CLLC converter exerts smaller stress on the high-frequency transformer than the DAB converter. However, due to its similarities to the LLC converter, the CLLC converter exhibits similar design trade-offs as the LLC converter such as the ZVS condition and efficiency degradation for a wide voltage and power operating range. The controllability of CLLC converter is another challenge, as the voltage gain curve against frequency tends to be steady in specific frequency ranges [45]. To solve above issues, authors in [46] add an auxiliary transformer to help realize full load range ZVS while improving power regulation. A detailed parameter design methodology is provided in [47] to realize robust power regulation with a wide operating range.

In many cases, there is a desire to minimize the number of active devices in a topology. One way to achieve this is to utilize half-bridge equivalents of the converters shown in Fig. 3 including the widely used half-bridge LLC converter [48], [49] and dual half-bridge (DHB) converter [50], [51]. The half-bridge converters use only four active switches which reduces the cost. Comparing with the full-bridge version, the voltage applied is half of the dc link voltage. This feature is beneficial for the high-frequency transformer design when used in MV applications. However, the current stress on the active devices is doubled, and the degrees of freedom available for converter control are reduced. 


\section{$4^{\text {th }}$ International Conference on Modern Research in Science, Engineering and Technology}

5-7 MARCH 2021

BERLIN, GERMANY

\subsection{Non-isolated DC/DC converters:}

If the charging system is designed to exploit the isolation provided by a different power conversion stage of the fast charging system (for example the line-frequency transformer before the AC/DC front-end), a non-isolated DC/DC converter can be used instead of an isolated one, while still providing a floating power supply to the vehicle battery. In this discussion, we consider bidirectional non-isolated DC/DC converters for two reasons. First, the achievable efficiency of bidirectional converters is higher than the unidirectional ones due to synchronous rectification. Second, unlike isolated DC/DC converters, the bidirectional operation does not add more complexity to the control of non-isolated DC/DC converters. Although focusing on the bidirectional converters, the discussions also apply to corresponding unidirectional versions.

Considering the battery voltage is lower than the output voltage of the AC/DC front-end in most cases, a boost converter (from the battery point of view) in Fig. 4a is the simplest nonisolated topology to interface with the battery. The power rating of this converter is limited since the current is carried by a single switch. Also, the inductor size is large if the current ripple needs to be small.

To increase the current carrying capability and reduce the current ripple seen by the battery, two or more phase legs can be interleaved to form a multi-phase interleaved boost converter. Fig. 4b shows an interleaved boost converter with three phase legs. Due to its simple structure, good performance, and scalability to high power, this topology has been widely explored in literature for EV charging application [13], [14], [52], [53], [54]. In [14], an EV charger prototype is reported to have six phase legs connected in parallel and interleaved to reach $30 \mathrm{~kW}$. In [53], a $100 \mathrm{~kW}$ three-phase interleaved boost converter is designed to work in discontinuous conduction mode (DCM). The inductors are small enough to allow both positive and negative current in one switching period, achieving ZVS for all switches. With an optimized inductor design, the system size can be reduced and efficiency improved. In [54], an interleaved boost converter implementation operating in DCM utilizes the partial power concept by separating the bus voltage into two parts in series. With the converter connecting to part of the bus voltage, switches with lower voltage ratings can be used, potentially reducing losses. The drawback of this method is the extra hardware and control effort to balance the two DC bus voltages.

Another topology that offers better harmonic performance than the boost converter is the three-level boost converter [55] and its bidirectional version [56] as shown in Fig. 4c and Fig. $4 \mathrm{~d}$, respectively. The current ripple in the three-level boost converter is only one fourth of that in the boost converter if the same inductor is used, which implies a smaller inductor can be used to meet the current ripple specifications. In [57], the performance of a boost converter, a two-phase interleaved boost converter and a three-level boost converter are compared. The work shows that the three-level boost converter can increase efficiency and reduce the size of the magnetic components. However, the three-level boost converter has high electromagnetic interference (EMI) in terms of common mode noise, which could have a negative impact on the battery system. Further, the three-level boost converters cannot be paralleled easily. If there is a phase shift between paralleled three-level boost phase legs, large circulating currents will result unless interphase inductors are used between phase legs. For high power applications when multiple parallel phase legs are necessary, circulating currents can be suppressed by either switching the phase legs synchronously [58], which eliminates the inductor size reduction due to interleaving, or by using an integrated inductors that suppresses 
the circulating currents [59]. Due to its three-level nature, the three-level boost converter is suitable for interfacing the EV battery with a bipolar bus such as the EV charging station topologies proposed in [60], [61] and [62].

Another potential three-level topology for fast chargers is a flying capacitor converter shown in Fig. 4e. This three-level topology allows for the use of a smaller inductor compared to a boost converter. Also, the power rating of the converter can be easily increased by paralleling and interleaving multiple phase legs. However, the short circuit protection design is challenging due to the presence of the flying capacitor. In addition, the switching commutation loop of the flying capacitor converter involving the uppermost and lowermost devices is larger than that of boost converter and three-level boost converter [63], which may cause undesired voltage overshoot during switching. In [64], a $55 \mathrm{~kW}$ flying capacitor converter prototype boosts the battery voltage three times to the traction inverter bus voltage. The efficiency is above $96.5 \%$ over the entire power range. However, to the authors' best knowledge, currently no proposed or implemented dc fast charger uses the flying capacitor converter.

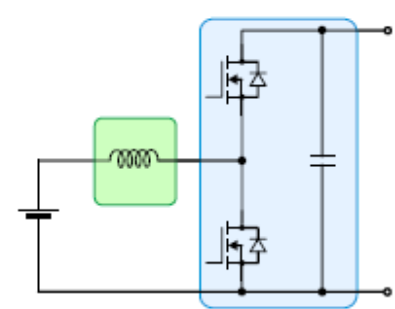

(a) Boost converter

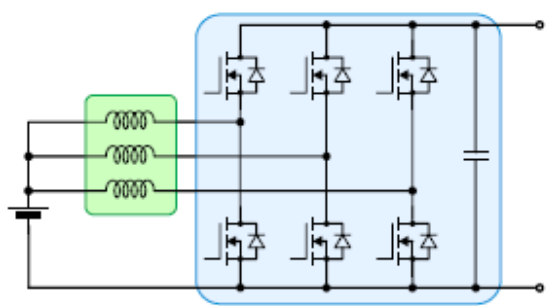

(b) Interleaved boost converter
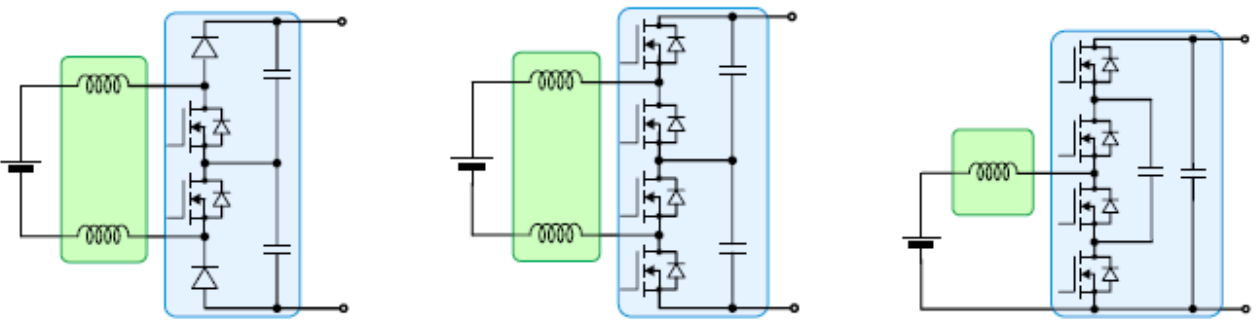

Figure 4: Non-isolated DC-DC converter topologies for dc fast chargers

TABLE 4: Comparison of different non-isolated DC/DC converter topologies for dc fast chargers

\begin{tabular}{|c|c|l|}
\hline Converter & Switches/Diodes & \multicolumn{1}{|c|}{ Major Advantages and Disadvantages } \\
\hline $\begin{array}{c}\text { Boost converter } \\
\text { (Fig.45a) }\end{array}$ & $2 / 0$ & $\begin{array}{l}\text { Simple control. } \\
\text { Limited current and voltage capability. }\end{array}$ \\
\hline $\begin{array}{c}\text { Interleaved boost } \\
\text { converter (Fig.4b) }\end{array}$ & $6 / 0$ & $\begin{array}{l}\text { Increased current capability; low current ripple; } \\
\text { simple control; good scalability. } \\
\text { Limited voltage capability. }\end{array}$ \\
\hline $\begin{array}{c}\text { Three-level boost } \\
\text { converter (Fig.4d) }\end{array}$ & $4 / 0$ & $\begin{array}{l}\text { Increased voltage capability; reduced current } \\
\text { ripple. } \\
\text { Not for interleaving due to circultaing current. }\end{array}$ \\
\hline $\begin{array}{c}\text { Flying capacitor } \\
\text { converter (Fig.4e) }\end{array}$ & $4 / 0$ & $\begin{array}{l}\text { Increased voltage capability; good scalability. } \\
\text { Difficult short-circuit protection. }\end{array}$ \\
\hline
\end{tabular}


While the state-of-the-art dc fast chargers requires MV-to-LV line-frequency transformers, another solution is the proposed closed-loop DC-DC buck converter based battery charger for charging a PEV using the constant-current and constant-voltage (CCCV) charging scheme. This buck type dc fast charger provides rectification, voltage step down at unity power factor (UPF) without the need for a PFC. Its control is simple, utilizes less electronic components, easy protection against reverse current from the battery, provides size reduction, and efficiency improvement over the state-of-the-art implementations, by minimizing the power lost in the conversion process.

The proposed system model consists of three parts: Three-phase Rectifier, Buck converter and Battery system. Fig. 5 is the block diagram of the system.

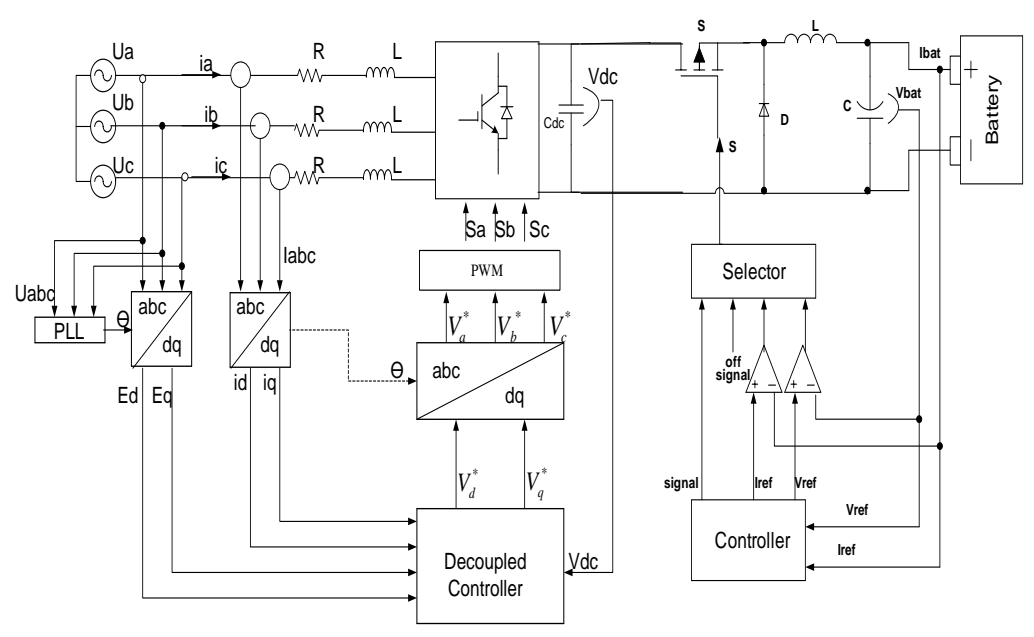

Figure 5. The proposed system block diagram

\section{Three-phase Controlled Rectifier}

\subsection{Topologies}

Rectifiers convert the utility ac supply voltage to a dc voltage with a fixed or ad-justable magnitude. They are used in various industrial applications such as electronic ballasts, household electric appliances, battery charging, motor drives, power conversion, High Voltage Direct Current (HVDC), etc. [65]. Although rectifiers provide a dc output, they differ in characteristics such as ac-side harmonics, power factor, and efficiency as well as output ripple and mean voltage. Due to the wide range of applications, different configurations and classifications occur.

Rectifiers are generally classified according to the function and the load type into either: a voltage source rectifier (VSR) or a current source rectifier (CSR) [66].

AC-dc converters are commonly classified according to the topology, as shown in fig. 6, into line or naturally commutated rectifiers and forced commutated rectifiers. Each can be classified into either regenerative or non-regenerative [67]. In applications such as drives, downhill conveyors, locomotives, cranes, etc., the energy flow can be reversed during operation. The rectifier should be able to deliver energy back to the ac power supply, hence is 
considered a regenerative rectifier [68]. This rectifier is termed a line-side commutated converter.

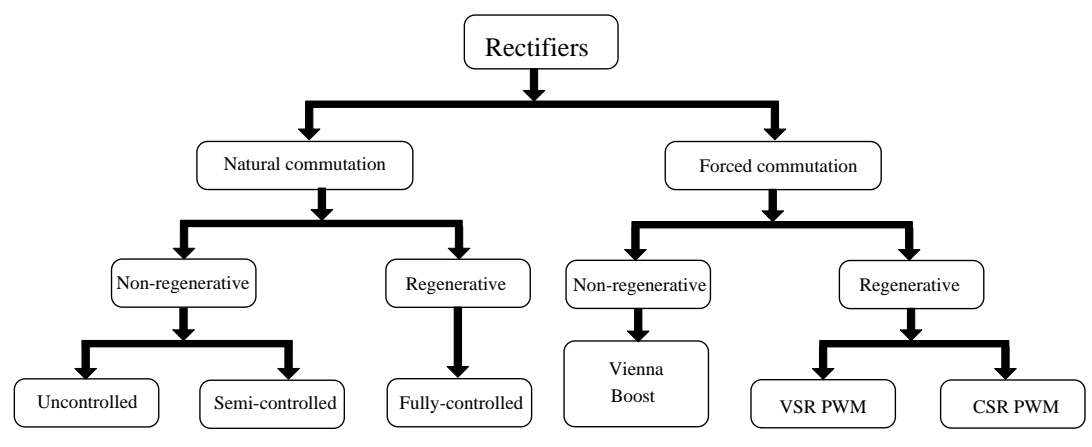

Figure 6. Classification of rectifiers

Universal bridge topology of a bidirectional regenerative Pulse Width Modulation (PWM) Voltage Source Rectifier (VSR) is adopted in this paper. The VSR can operate as a voltagesource inverter (VSI) and as a rectifier when reversing the power flow from the load to the dclink. The power circuit of the VSR is shown in fig. 7. The dc link output voltage is controlled at voltage level greater than the maximum input line voltage. Therefore this converter operates as a voltage booster. The input current is controlled to be synchronized with supply voltage to improve the input power factor [69], [70], [71], [72].

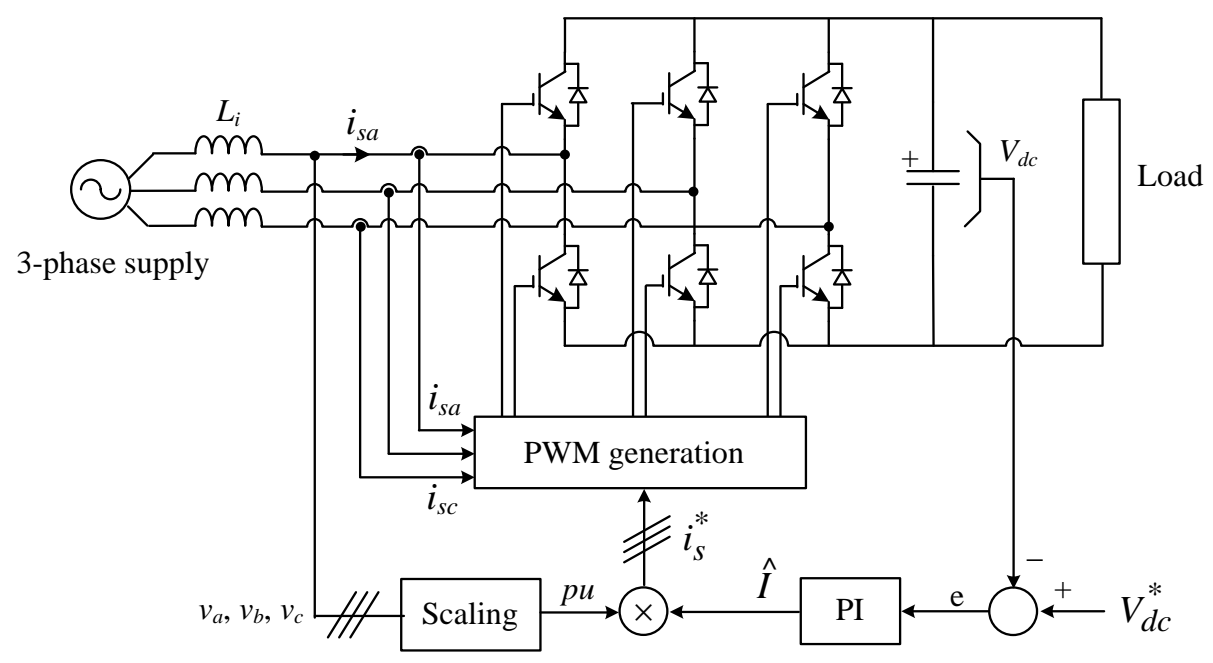

Figure 7. Voltage source PWM rectifier

Different PWM techniques can be used to determine the on and off conditions of inverter switches, such as Sinusoidal Pulse Width Modulation (SPWM), Space Vector Modulation (SVM), and Super High Efficiency (SHE) [73]. The SPWM is adopted in this paper.

To achieve unity power factor (UPF) operation and bi-directional energy flow ca-pability of the rectifier, the universal topology is adopted to build a low-cost three-phase module rectifier. However, poor immunity to shoot-through faults, high per-unit current rating, and high switching losses are some of the draw backs of this topology [74]. 


\subsubsection{Steady state operation}

The basic diagram of the three- phase boost converter is shown in the figure below (Fig. 8 ). The line voltage that comes from the grid is denoted $\mathrm{uL}$ and the bridge converter voltage is denoted $\mathrm{uS}$ and can be controlled from the dc- side. Diagrams for both rectifi-cation and regeneration operation at UPF are shown in Fig. 9.

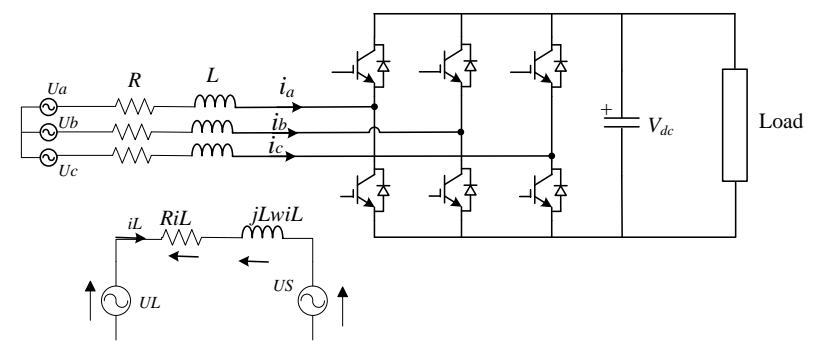

Figure 8. Rectifier Schematic

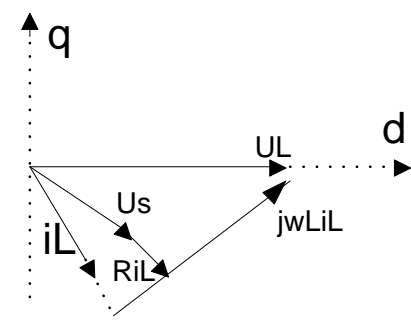

(a)

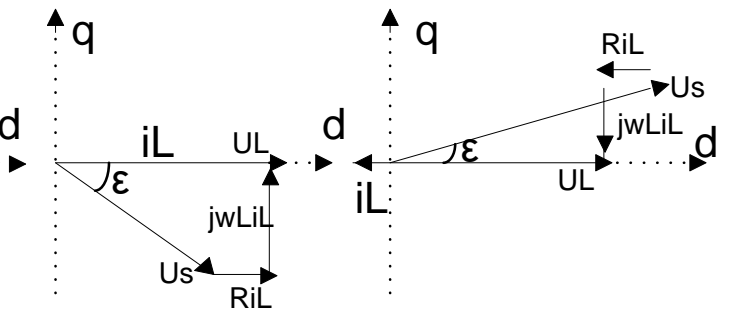

(b)

(c)

Figure 9. (a) General phasor diagram (b) Rectification at UPF (c) Regeneration at UPF.

By controlling the voltage drop across the inductance $\mathrm{L}$ that connects the line and the converter, we can control the line current iL. Controlling the amplitude of converter voltage $\mathrm{uS}$ and the phase angle, $\varepsilon$ we indirectly control the phase and amplitude of the line current. By doing so, the average value (i.e the mean) and sign of the dc current is subject to control that is proportional to the active power that is conducted through the converter. We can independently control the reactive power with a shift of the fundamental harmonic current iL with respect to voltage uL [74].

Remark: A current source character is brought by the inductors connected between the line and the rectifier which result in the boost feature of the converter [74].

\subsubsection{Mathematical Model}

The three- phase line voltage and current are:

$$
\begin{gathered}
U a=E m \cos (w t) \\
U b=E m \cos (w t-2 \pi / 3) \\
U c=E m \cos (w t-4 \pi / 3) \\
i a=I m \cos (w t+\emptyset)
\end{gathered}
$$




$$
\begin{aligned}
& i b=\operatorname{Im} \cos (w t+\emptyset-2 \pi / 3) \\
& i c=\operatorname{Im} \cos (w t+\emptyset-4 \pi / 3)
\end{aligned}
$$

And since there is no neutral connection here, equation 7 is obtained:

$$
i a+i b+i c=0
$$

A three- phase system can be described with only two components $\alpha$ and $\beta$ (real and imaginary respectively). Furthermore, we call a space vector the quantity [75], [76].

$$
\begin{aligned}
V s(t)=V \alpha(t)+j \beta(t) \\
=2 / 3 K\left(V a(t)+V b(t) e^{j 2 \pi / 3}+V c(t) e^{j 4 \pi / 3}\right.
\end{aligned}
$$

Where $\mathrm{K}$ is a scaling constant (amplitude invariant $\mathrm{K}=1$, RMSinvariant $K=1 / \sqrt{ } 2$, power invariant $K=\sqrt{ }(3 / 2)$ ).

\subsubsection{Rectifier ABC Model}

$$
\begin{aligned}
& U S a b=(S a-S b) U d c \\
& U S b c=(S b-S c) U d c \\
& U S c a=(S c-S a) U d c
\end{aligned}
$$

With phase $\mathrm{i}=\mathrm{a}, \mathrm{b}, \mathrm{c}$ and $\mathrm{Si}$ the switching function defined by:

$$
\mathrm{Si}=\left\{\begin{array}{c}
1 \text { upper switch ON } \\
0 \text { bottom switch ON }
\end{array}\right.
$$

$$
\begin{aligned}
& u S a=f a \cdot u d c \\
& u S b=f b \cdot u d c \\
& u S c=f c \cdot u d c
\end{aligned}
$$

$$
\begin{aligned}
f a=S a-S *= & S a-1 / 3(S a+S b+S c) \\
=2 S a-(S b+S c) / 3 & (15)
\end{aligned}
$$

$$
\begin{aligned}
& f b=2 S b-(S a+S c) / 3 \\
& f c=2 S c-(S a+S b) / 3
\end{aligned}
$$

(fabc are $0, \pm 1 / 3$ or $\pm 2 / 3$ )

The rectifier is defined by four equations, one for each phase voltage and one for the currents (dc- link): 
$4^{\text {th }}$ International Conference on Modern Research in

\section{Science, Engineering and Technology}

$\left[\begin{array}{l}U a \\ U b \\ U c\end{array}\right]=R\left[\begin{array}{l}i a \\ i b \\ i c\end{array}\right]+L \frac{d i}{d t}\left[\begin{array}{l}i a \\ i b \\ i c\end{array}\right]+\left[\begin{array}{l}U s a \\ U s b \\ U s c\end{array}\right]$

$C \frac{d u d c}{d t}=S a i a+S b i b+S c i c-i l o a d$

The combination of the previous equations can be represented as a block diagram:

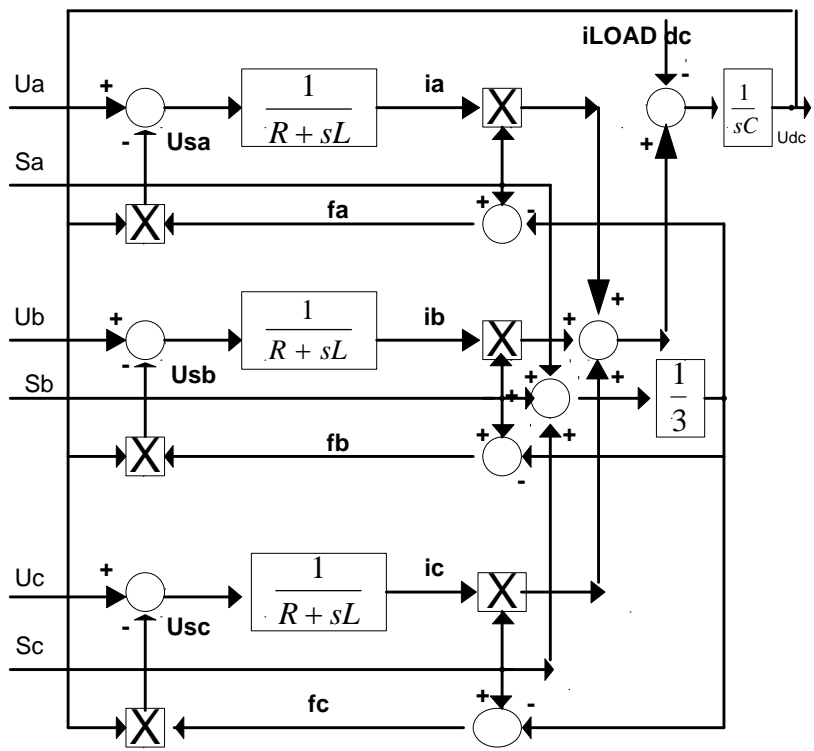

Figure 10. The Rectifier Model

2.1.4 Rectifier $\alpha \beta$ - Equations

$$
\begin{aligned}
& {\left[\begin{array}{l}
\alpha \\
\beta
\end{array}\right]=\left[\begin{array}{ccc}
\frac{2}{3} & \frac{-1}{3} & \frac{-1}{3} \\
0 & \frac{1}{\sqrt{3}} & \frac{-1}{\sqrt{3}}
\end{array}\right]\left[\begin{array}{l}
a \\
b \\
c
\end{array}\right]} \\
& {\left[\begin{array}{l}
a \\
b \\
c
\end{array}\right]=\left[\begin{array}{cc}
1 & 0 \\
\frac{-1}{2} & \frac{\sqrt{3}}{2} \\
\frac{-1}{2} & \frac{-\sqrt{3}}{2}
\end{array}\right]\left[\begin{array}{l}
\alpha \\
\beta
\end{array}\right]}
\end{aligned}
$$

Then, applying this transformation we can find the voltage equations in $\alpha \beta$ - coordinates:

$$
\begin{aligned}
& {\left[\begin{array}{l}
U \alpha \\
U \beta
\end{array}\right]=\mathrm{R}\left[\begin{array}{l}
i \alpha \\
i \beta
\end{array}\right]+\mathrm{L} \frac{d}{d t}\left[\begin{array}{l}
i \alpha \\
i \beta
\end{array}\right]+\left[\begin{array}{l}
U s \alpha \\
U s \beta
\end{array}\right]} \\
& C \frac{d u d c}{d t}=3 / 2(S \alpha i \alpha+S \beta i \beta)-i l o a d
\end{aligned}
$$


$4^{\text {th }}$ International Conference on Modern Research in

\section{Science, Engineering and Technology}

5-7 MARCH 2021

BERLIN, GERMANY

Here, we will apply the Park transformation:

$$
\mathrm{V}_{d q}=\mathrm{V}^{c} e^{-j \theta}
$$

Where $\mathrm{V}^{\mathrm{c}}$ is a space vector $\left(\mathrm{v}^{\mathrm{c}}=\mathrm{v}_{\alpha}+\mathrm{jv} \beta\right)$. We get:

$$
U^{S}=\mathrm{R} i^{S}+L_{d t}^{d i^{S}}+u_{s}^{S}
$$

$$
u_{d q} e^{j \theta}=\mathrm{R} i_{d q} e^{j \theta}+\mathrm{L}\left(e^{j \theta}\left(j w i_{d q}+\frac{d i_{d q}}{d t}\right)\right)+e^{j \theta} u_{s d q}
$$

$$
u_{d q}=\mathrm{R} i_{d q}+\mathrm{L} \frac{d i_{d q}}{d t}+j L w i_{d q}+u_{s d q}
$$

And finally, with separation of Real and Imaginary part we obtain:

$$
\begin{aligned}
& u_{d}=\mathrm{R} i_{d}+\mathrm{L} \frac{d i_{d}}{d t}-w L i_{q}+u_{s d} \\
& u_{q}=\mathrm{R} i_{q}+\mathrm{L} \frac{d i_{q}}{d t}-w L i_{d}+u_{s q}
\end{aligned}
$$

\subsubsection{Instantaneous Power[75]}

From the well-known relation Power, $\mathrm{P}=\operatorname{Real}\left\{\mathrm{V} \mathrm{I}{ }^{*}\right\}$ for single phase Root Mean Square, RMS- value- scaled phasors $\mathrm{V}$ and I (“**" indicates complex conjugate), we know that instantaneous power for three- phase system will be proportional to:

$$
\operatorname{Re}\left\{\mathrm{vs}(\mathrm{is})^{*}\right\}=\operatorname{Re}\{\mathrm{vdq}(\mathrm{idq}) *\}
$$

Note that the formula is independent of the coordinate system. From the space vector definition we get (the time argument "( $\mathrm{t})$ " is removed for simplicity):

$$
\begin{aligned}
& v^{S}\left(i^{s}\right) *=\left(\frac{2}{3} K\right)^{2}\left(v_{a}+v_{b} e^{j \frac{2 \pi}{3}}+v_{c} e^{j \frac{4 \pi}{3}}\right)+\left(i_{a}+i_{b} e^{j \frac{2 \pi}{3}}+i_{c} e^{j \frac{4 \pi}{3}}\right)^{*} \\
& =\left(\frac{2}{3} K\right)^{2}\left[v_{a} i_{a}+v_{b} i_{b}+v_{c} i_{c}+j \frac{1}{\sqrt{3}}\left(v_{a}\left(i_{c}-i_{b}\right)+v_{b}\left(i_{a}-i_{c}\right)+v_{c}\left(i_{b}-i_{a}\right)\right)\right]
\end{aligned}
$$

And finally the real part gives the active power:

$$
P=\frac{3}{2 K^{2}} \operatorname{Real}\left\{v^{s}\left(i^{s}\right) *\right\}=\frac{3}{2 K^{2}} \operatorname{Real}\left\{v^{d q}\left(i^{d q}\right) *\right\}=v_{a} i_{a}+v_{b} i_{b}+v_{c} i_{c}
$$

And with imaginary part we obtained the reactive power:

$$
Q=\frac{3}{2 K^{2}} I_{m}\left(v^{s}\left(i^{s}\right) *\right)=\frac{3}{2 K^{2}} I_{m}\left(\left(i^{d q}\right) *\right)
$$




$$
\left.=j \frac{1}{\sqrt{3}}\left(v_{a}\left(i_{c}-i_{b}\right)+v_{b}\left(i_{a}-i_{c}\right)+v_{c}\left(i_{b}-i_{a}\right)\right)\right]
$$

\subsubsection{Limitations}

To properly operate the rectifier, there is a need for a minimum dc-link voltage which will help in obtaining undistorted current waveforms. Negative polarization of the six diodes of the rectifier will help us achieve full control of the rectifier. By ensuring a dc-link voltage greater than the peak dc-voltage generated by the diodes alone, will keep the diodes blocked. As far the diode rectifier theory, the maximum dc output voltage is the peak value of line to line Root Mean Square (RMS) voltage [74].

$$
\text { VDCMIN }>\sqrt{ } 2 \text { VLL }(R M S)=\sqrt{ } 2 \cdot \sqrt{ } 3 \cdot \operatorname{VLN}(\mathrm{RMS})
$$

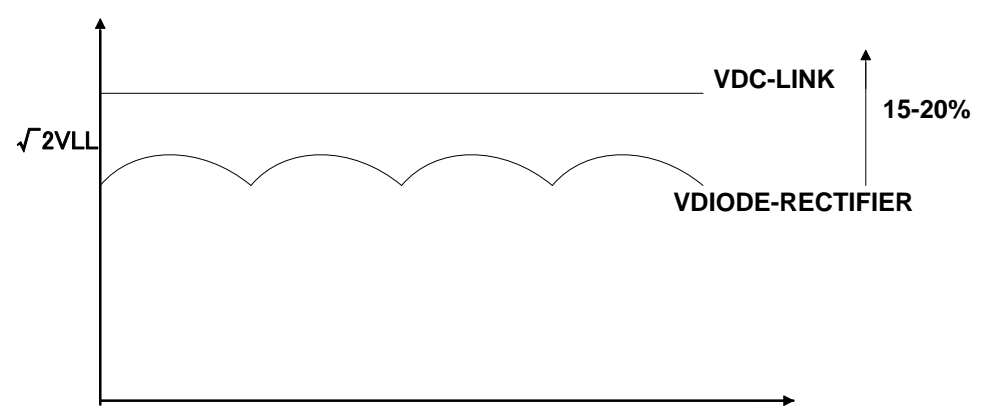

Figure 11. dc-link voltage condition

Better select a dc- link voltage about $15-20 \%$ higher than $\sqrt{ } 2$ VLL. For the simulation, 625 $\mathrm{V}$ is selected.

IMPORTANT: The previous voltage VLL(RMS) corresponds to the converter voltage (Us). There is no line impedance taking in account here.

Nevertheless, if there is no line impedance $(\mathrm{R}=0 \Omega, \mathrm{L}=0 \mathrm{H})$ we can continue to write the equation (35) according to the amplitude of supply voltage Em:

VDCMIN $>\sqrt{ } 2 \cdot \sqrt{3}$. VLN $($ RMS $)=\sqrt{ } 3 \mathrm{EM}(36)$

ATTENTION: This is a true definition but doesn't apply in all situation [74]

The dc- link voltage depends on the PWM method. In our case, we will use SPWM. In this case the maximum reference voltage is Vdc/2 (Fig. 12 [77])

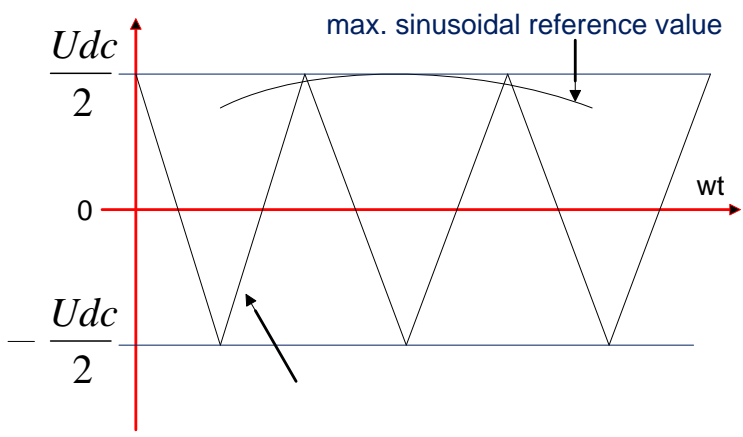


Figure 12. Maximum sinusoidal reference voltage (converter voltage Us) for SPWM

Finally, our minimum DC- link voltage will be:

$$
\begin{aligned}
& V_{L N(\text { peak })}=\frac{V_{D C}}{2} \\
& \frac{V_{L L(r m s)}}{\sqrt{3}} \sqrt{2}=\frac{V_{D C}}{2}
\end{aligned}
$$

$$
V_{D C \text { min }}>2 V_{L N(\text { peak })}=\frac{2 \sqrt{2}}{\sqrt{3}} V_{L L(r m s)}=1.663 V_{L L(r m s)}
$$

A minimum dc-link voltage is defined in the book [74] by taking into account the line inductance. Our case is amplitude invariant (they assume a maximum converter voltage to be $2 / 3 \mathrm{Vdc}$, which is the radius of switching hexagon). For power invariant, the dc-link voltage will be $\sqrt{3} / 2 \mathrm{Vdc}$. They define a dc-Link voltage as:

$$
V_{d c}>\sqrt{\left(3\left[E_{m}^{2}+(w L i d)^{2}\right]\right)}
$$

It is observable that the $\mathrm{R}$ is ignored and if there is no inductance voltage, $\mathrm{L}=0$ we can rewrite equation 40 for $\mathrm{Vdcmin}>\sqrt{3} \mathrm{EM}$. And hence from this equation the maximum inductance value can be calculated as:

$$
L<\frac{\sqrt{ }\left(\frac{V_{D C}^{2}}{3}-E_{m}^{2}\right)}{\text { wid }}
$$

A high current ripple results from a low inductance value and will make the design more reliant on the line impedance. As indicated by [74], a greater value of the inductance will give a low current ripple, however at the same time decreases the activity scope of the rectifier. The current is controlled by the voltage drop across the inductance. This voltage drop is constrained by the voltage of the rectifier however its maximal worth is restricted by the dclink voltage. Therefore, a high current (high power) through the inductance needs either a high dc- link voltage or a low inductance (low impedance).

\subsubsection{Voltage oriented control strategy}

The Voltage Oriented Control (VOC) ensures high unique and static execution through an interior current control loop. Be that as it may, the quality relies chiefly upon the current control procedure. 


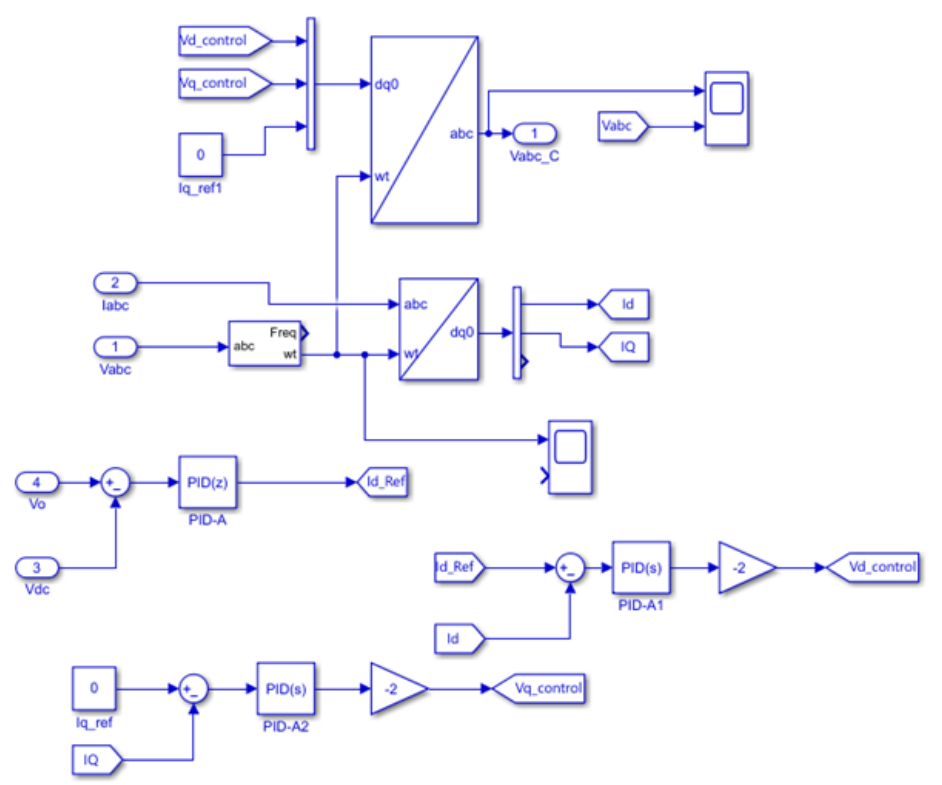

Figure 13. VOC Block Scheme

The VOC is near Field Oriented Control for induction motor. The strategy depends on the change between fixed directions $\alpha \beta$ and synchronous rotating coordinates dq. This methodology ensures:

- Quick transient response

- High static execution through inward current control loop

Thus, the performance relies upon the nature of the current control loop applied.

We can discover a few systems that can be applied for current control. A generally utilized plan for elite current control is the dq coordinated regulator, in which the regulated currents are DC quantities. This wipes out steady- state errors.

\subsubsection{The rectifier closed loop system block diagram}




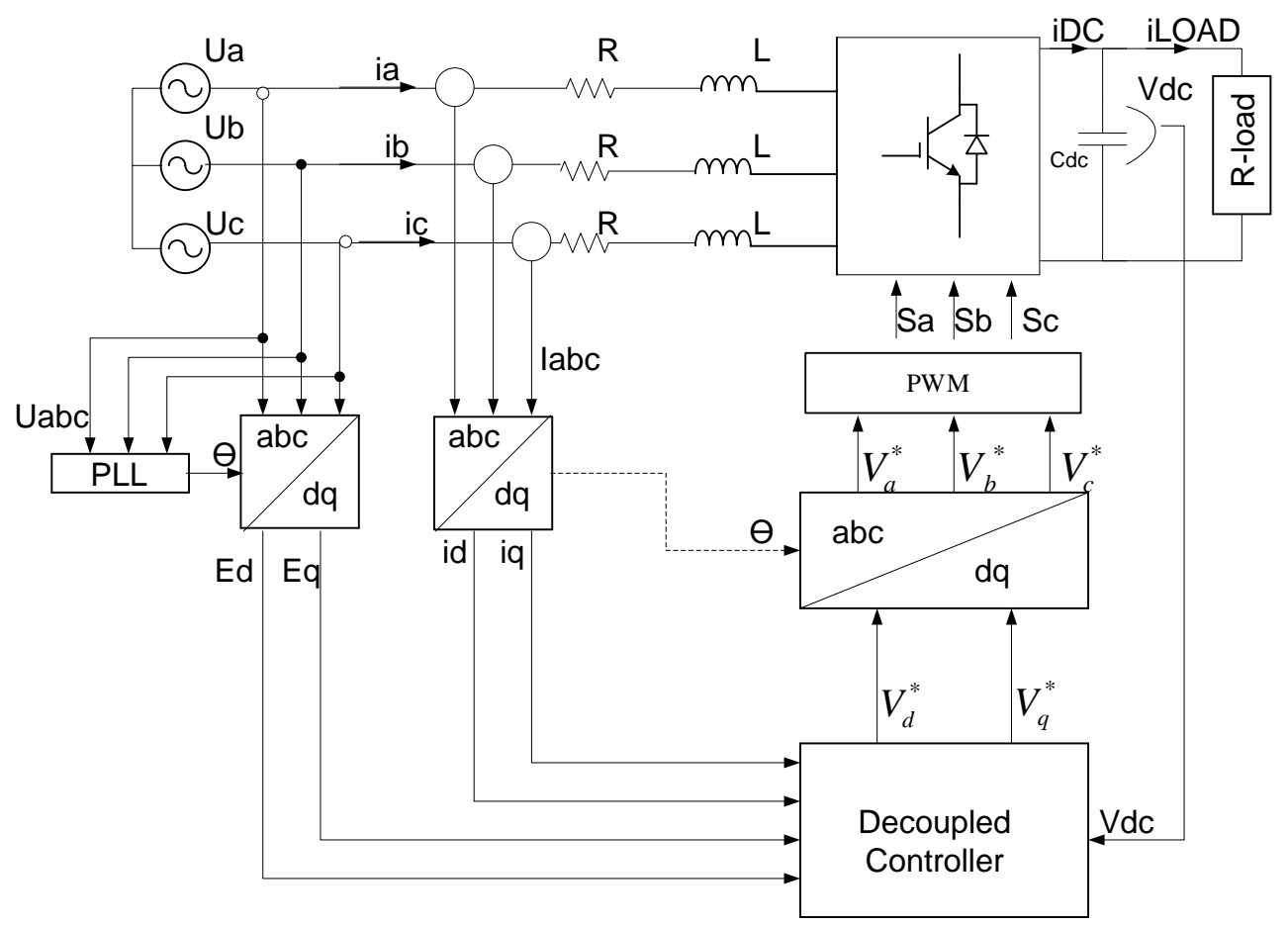

Figure 14. The rectifier closed loop system block diagram

- At the beginning, the Phase Locked Loop (PLL) is feed from the line voltage Uabc. Then the voltage angle is determined and utilized for three-phase to dqcoordinate transformation of the line current and voltage.

- Then the dq- coordinate values and the dc- link voltage esteem are utilized in a decoupled regulator.

- At the last stage, the reference voltages generated by the regulator are shipped to the PWM block to make the switching patterns Sabc ( $S=1$ implies upper switch $\mathrm{ON}$, lower switch OFF; $\mathrm{S}=0$ implies upper switch $\mathrm{OFF}$, lower switch $\mathrm{ON}$ ).

Comment: The converter voltage Us and the reference voltage from the regulator are in correspondence.

The overall rectifier system detailed above will be simulated in Matrix Laboratory, MATLAB/Simulink. As indicated by Fig. 14, there will be four principle parts in this rectifier model: the PLL, a decoupled regulator/controller consisting of a current and voltage regulator, a PWM block, and a rectifier model (grid impedance Resistance, R and inductor, L included).

\subsection{9 abc to dq0 transformation and vice versa}

The abc to dq0 block uses a Park transformation to transform a three-phase (abc) signal to a dq0 rotating reference frame.

Benefits of abc to dq0 conversion:

- To reduce complexity of the system with dc values instead of ac values. 


\section{$4^{\text {th }}$ International Conference on Modern Research in Science, Engineering and Technology}

- The DC quantities facilitate easier filtering and control. It is much easier to design a controller for the dq model and one can use a regular Proportional Integral Derivative, PID which is not possible to apply directly on a regular ABC model.

- Independent control of active and reactive power is easily achieved by controlling the resulting dc quantities.

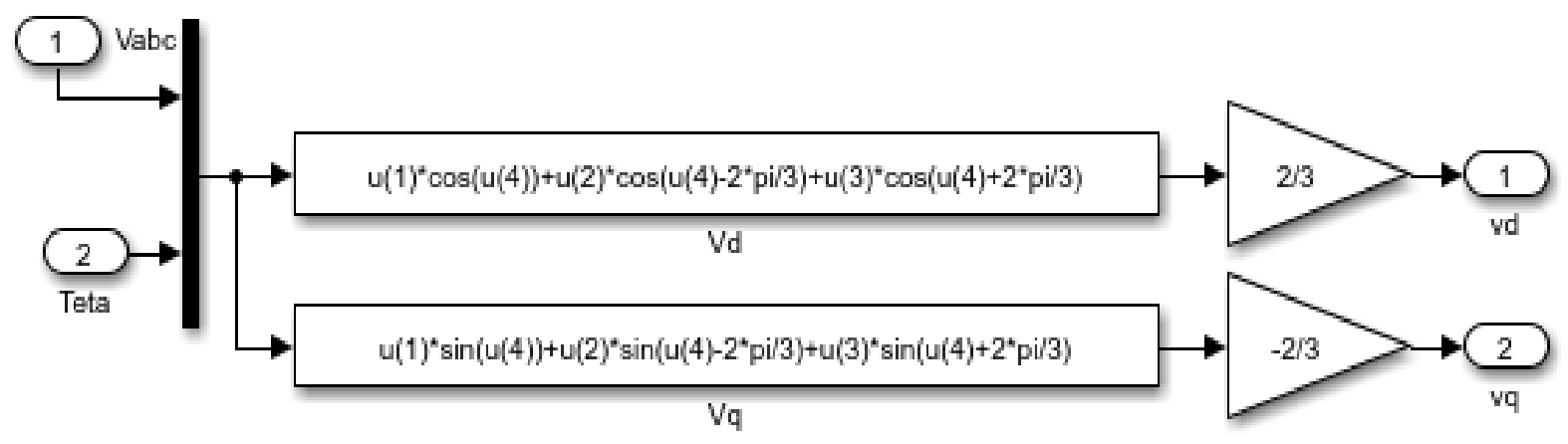

Figure 15. Vabc to Vdq

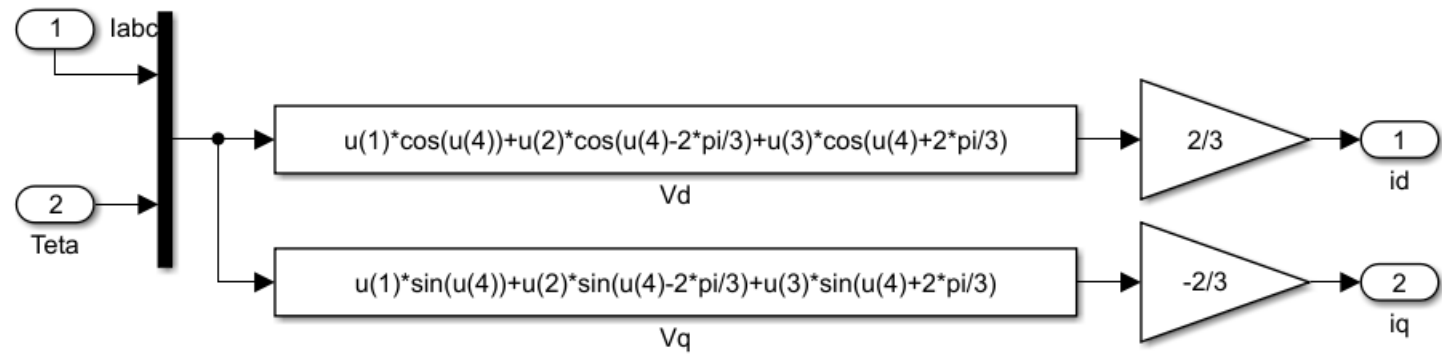

Figure 16. Iabc to Idq

Inverse Park transformation is utilized to convert a time-domain direct, quadrature, and zero components in a rotating reference frame to the components of a three-phase system. There is no zero component in a balanced system.

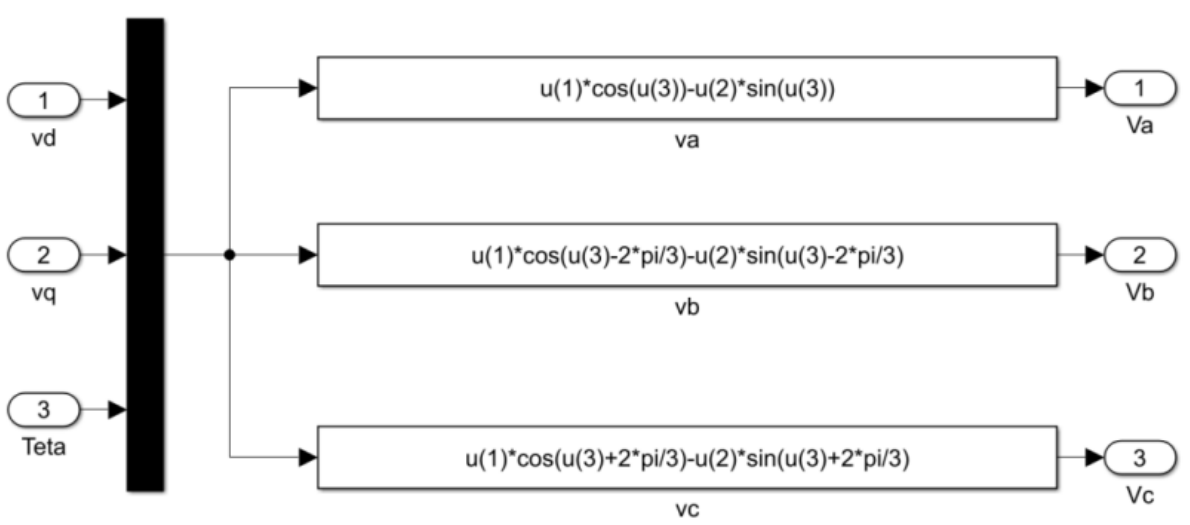

Figure 17. dq to abc transformation

\subsubsection{Decoupled Controller}


$4^{\text {th }}$ International Conference on Modern Research in

Science, Engineering and Technology

5-7 MARCH 2021

BERLIN, GERMANY

Decoupled controller with current controller and the dc- link voltage controller:

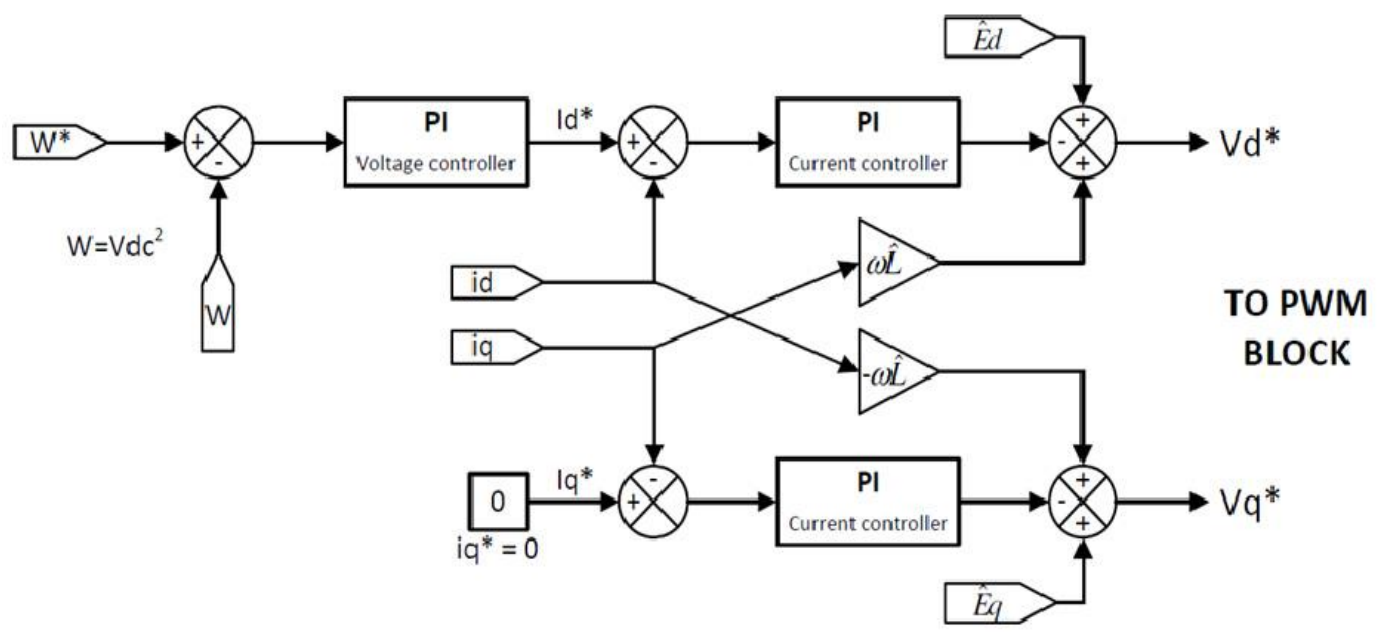

Figure 18. Decoupled controller

\subsubsection{Overall rectifier simulation}

The simulation of the system is done in MATLAB Simulink based on the VOC strategy. VOC implemented in synchronous rotating dq frame to control active and reactive power separately by controlling currents in $\mathrm{d}$ and $\mathrm{q}$ axes respectively.

The simulink model below is created for three phase SPWM AC-DC boost converter. A abc-dq control loop is implemented for unity power factor (reactive component of the current, i_q ${ }^{\wedge *}$ set to zero). The proposed model provides regulated output DC voltage with unity power factor and superior input power quality. The input voltage is three phase $230 \mathrm{~V} \mathrm{rms}, 50$ $\mathrm{Hz}$. The output voltage is also $625 \mathrm{~V}$ DC.

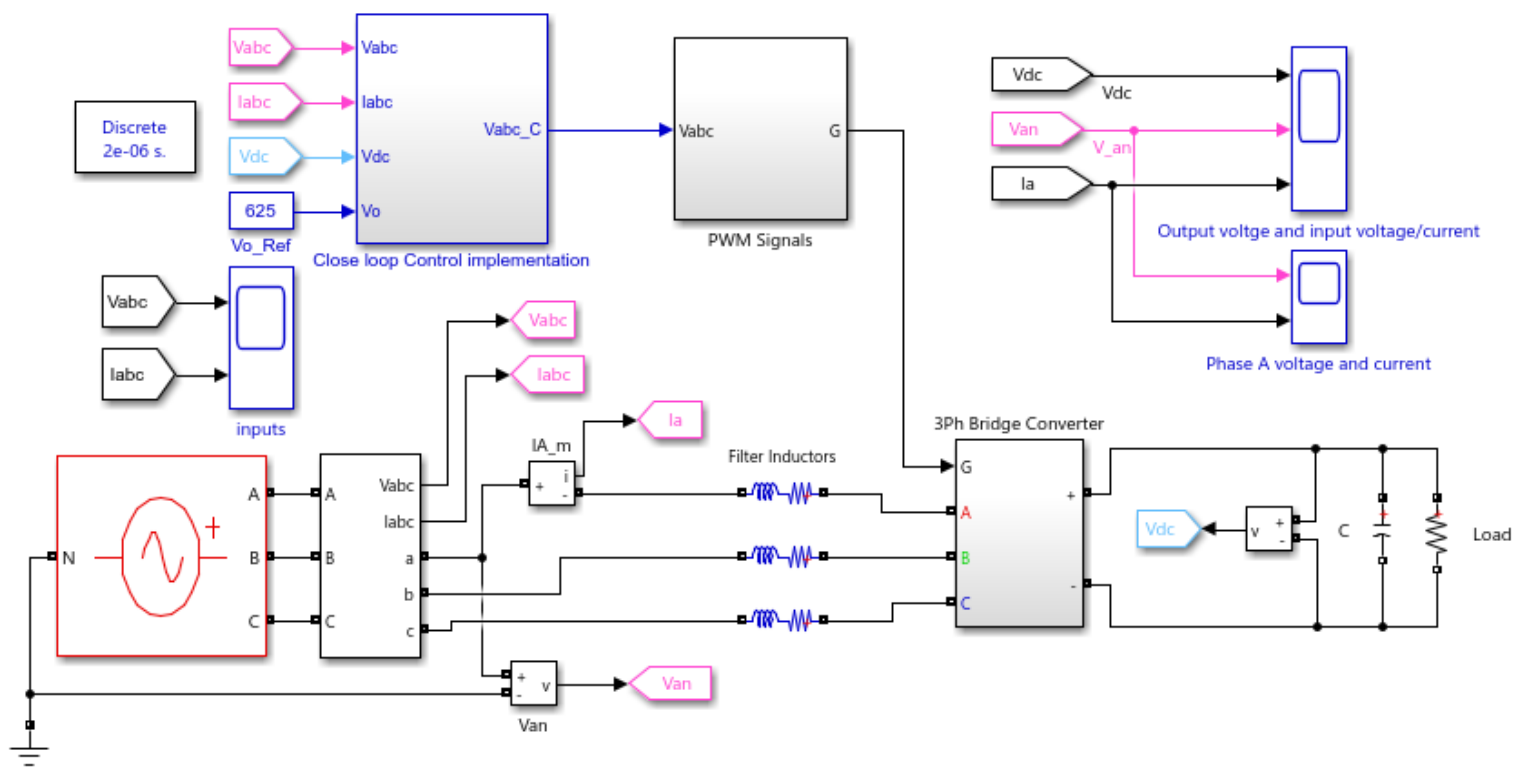

Figure 19. Three-Phase Rectifier 
$4^{\text {th }}$ International Conference on Modern Research in

Science, Engineering and Technology

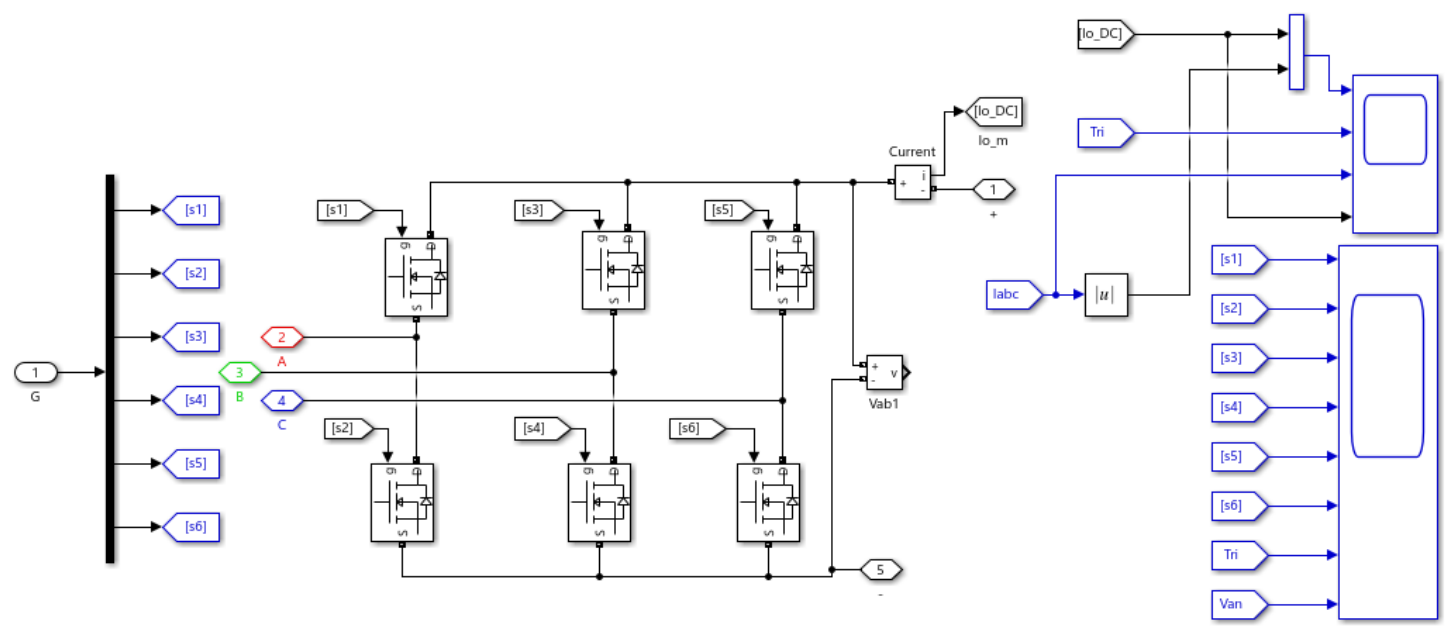

Figure 20. Inside the three-phase Bridge Converter (3-legs of the rectifier built using MOSFET switches)

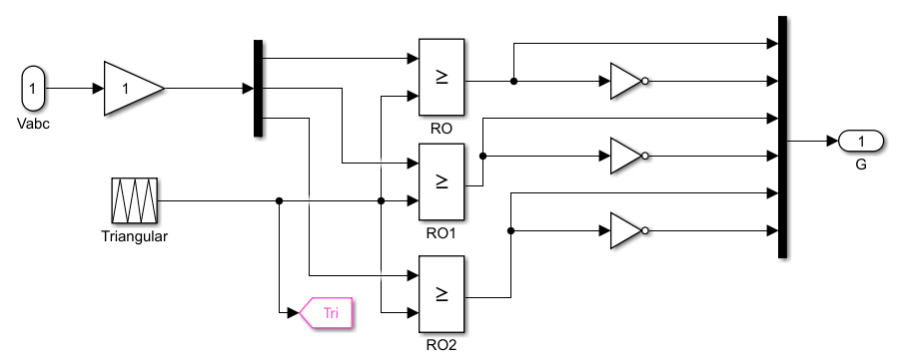

Figure 21. Inside the PWM Signal block (gate signals generation for the MOSFET switches of the rectifier)

Refer to fig. 13 for the closed loop control implementation.

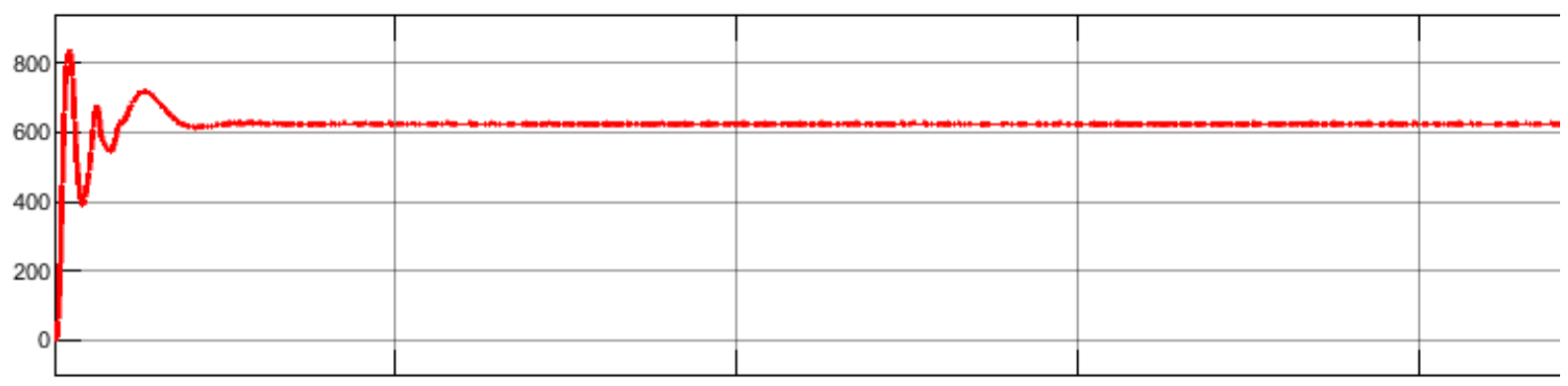

Figure 22. Vdc output of the rectifier in model 2, Vref (i.e desired output) is set to $625 \mathrm{~V}$ 
$4^{\text {th }}$ International Conference on Modern Research in

Science, Engineering and Technology

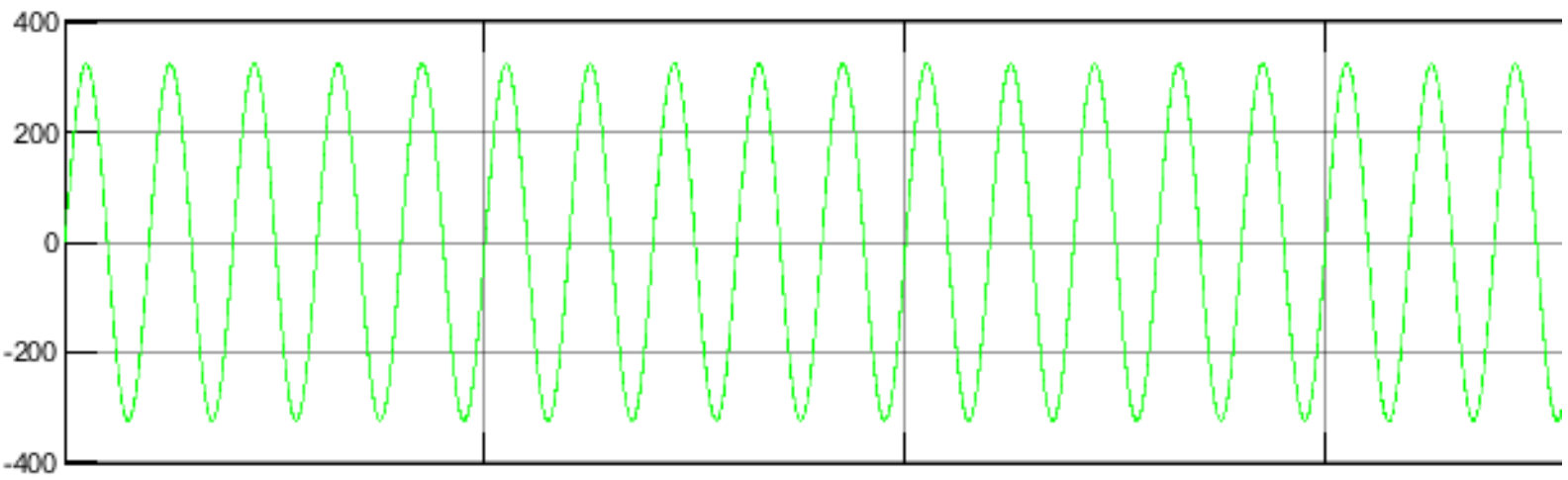

Figure 23. Phase-A input Voltage. The input voltage is three phase $230 \mathrm{~V} \mathrm{rms}, 50 \mathrm{~Hz}$

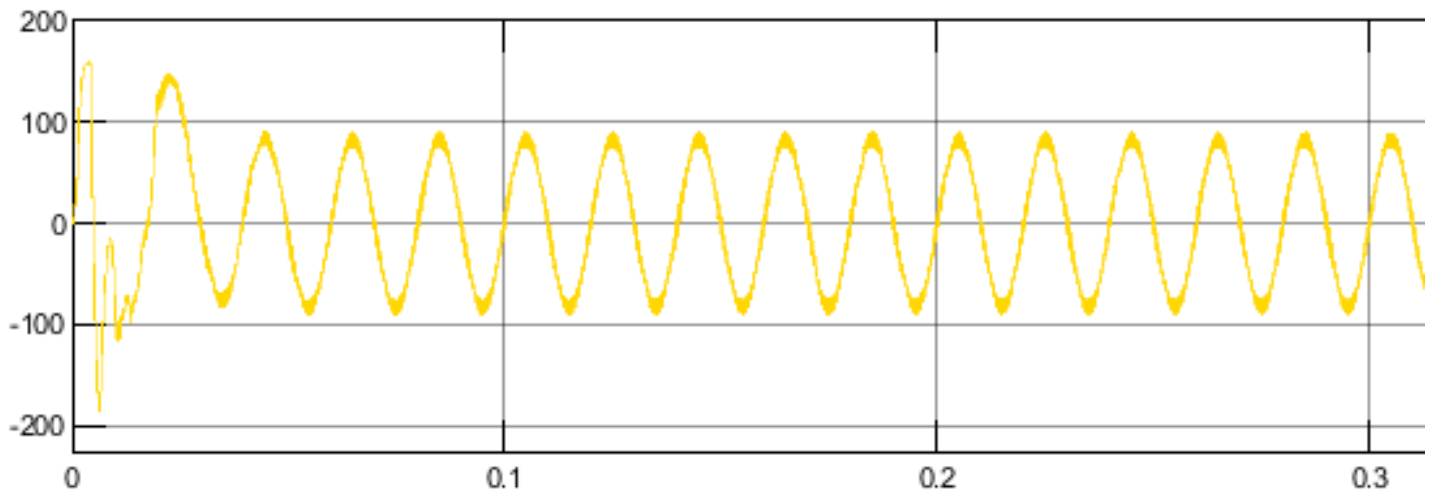

Figure 24. Phase-A input current

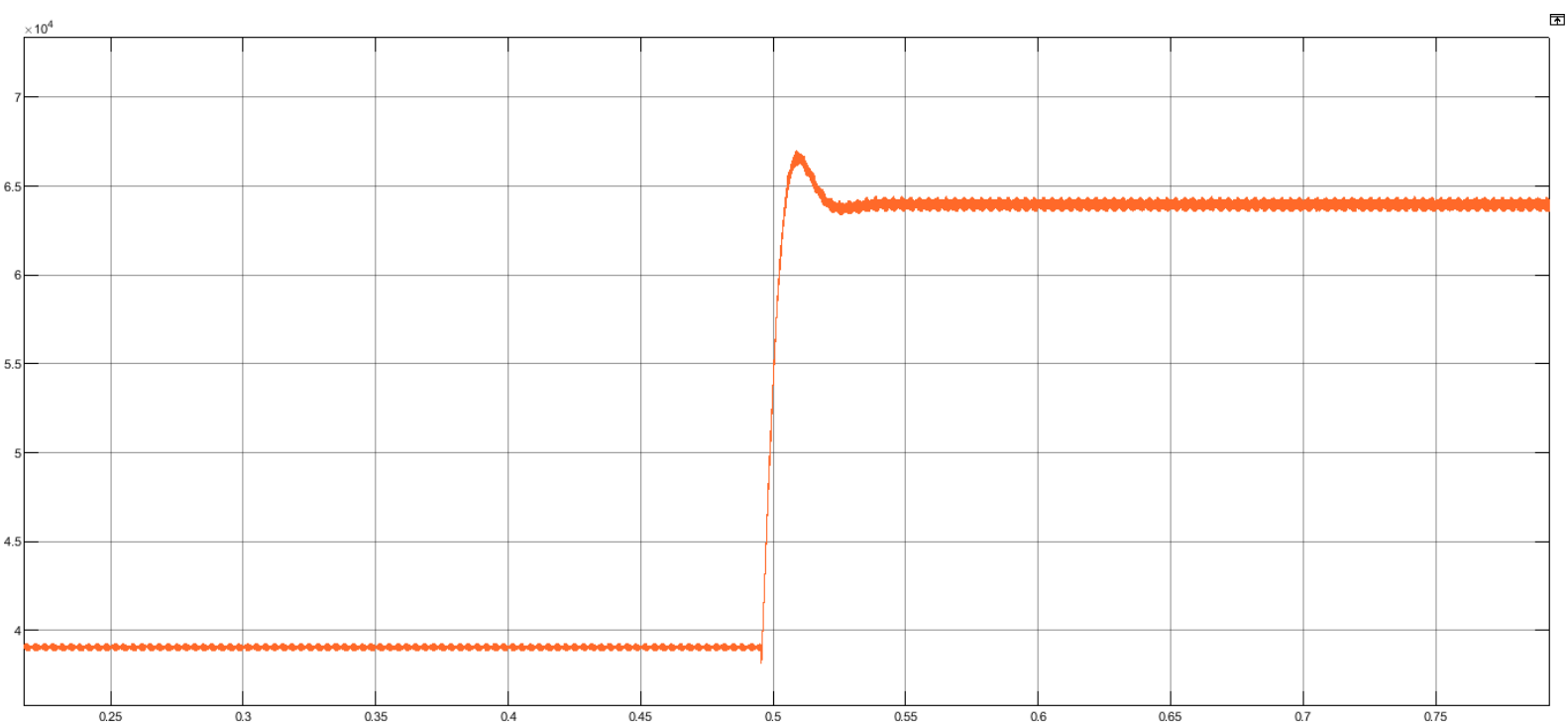

Figure 25. Power output of the rectifier. From $t=0$ to $t=0.5$ the reference voltage is kept at $625 \mathrm{~V}$ and power equals $39 \mathrm{~kW}$. From $\mathrm{t}=0.5$ to $\mathrm{t}=1.0$ the reference voltage is changed to $800 \mathrm{~V}$ and power equals $50 \mathrm{~kW}$.

Table 5. Rectifier table of values used in simulation 
$4^{\text {th }}$ International Conference on Modern Research in

Science, Engineering and Technology

BERLIN, GERMANY

\begin{tabular}{|c|l|}
\hline Parameter & Value \\
\hline$V_{\text {supply(peak })}$ & $220 \sqrt{2} \mathrm{~V}$ \\
\hline$f_{\text {supply }}$ & $50 \mathrm{~Hz}$ \\
\hline$R_{\text {line }}$ & $0.05 \Omega$ \\
\hline$L_{\text {line }}$ & $2 \mathrm{mH}$ \\
\hline $\mathrm{C}$ & $1500 \mu \mathrm{F}$ \\
\hline$R_{\text {load }}$ & $50 \Omega$ \\
\hline$V_{\text {reference }}$ & $625 \mathrm{~V}$ \\
\hline$P I D_{d}$ & $\mathrm{Kp}=2000, \mathrm{Ki}=100, \mathrm{Kd}=0$ \\
\hline$P I D_{q}$ & $\mathrm{Kp}=2000, \mathrm{Ki}=100, \mathrm{Kd}=0$ \\
\hline$f_{\text {switching }}$ & $5000 \mathrm{~Hz}$ \\
\hline
\end{tabular}

\section{Buck Converter Charging the Battery}

Here we simulated a dc to dc buck converter and battery charge controller to charge the battery using Constant Current Constant Voltage (CCCV) charging protocol.

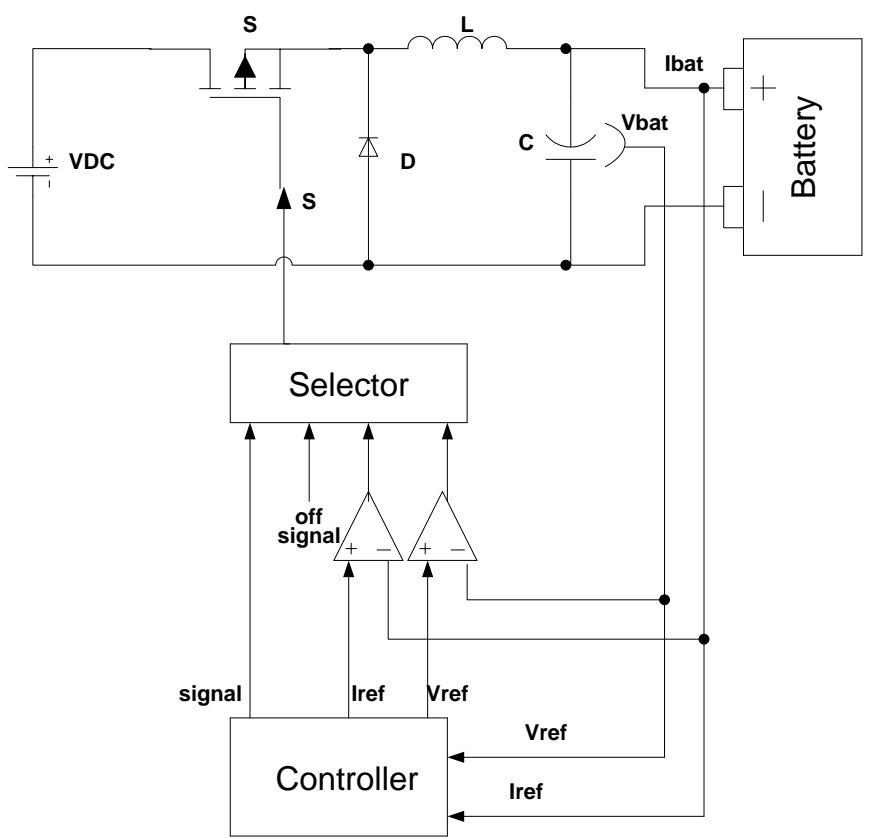

Figure 26. Buck Converter CCCV Battery Charger

\subsection{Operating principles of buck converter}

Buck, or step down converters produce an average output voltage lower than the input source voltage [78].

The output and input voltages are related as such:

$V_{\text {out }}=V_{\text {in }} \frac{T_{o n}}{T}$ 


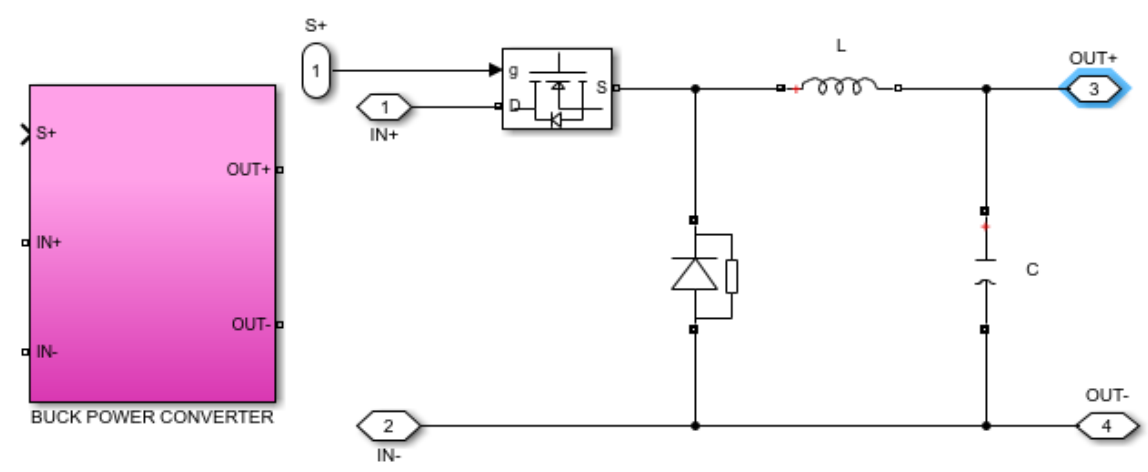

Figure 27. Buck Converter Subsystem in Simulink

The equation for inductor and capacitor selection according to [68] are as follows respectively:

$$
\begin{gathered}
L=\frac{V_{o}\left(V_{s}-V_{o}\right)}{f * V_{S} * \Delta I} \\
C=\frac{\Delta I}{8 * f * \Delta V_{c}}
\end{gathered}
$$

Where $\mathrm{Vs}$ is the input voltage, Vo is the output voltage, $\mathrm{f}$ is the switching frequency, $\Delta \mathrm{I}$ is the peak to peak ripple current of the inductor, and $\Delta \mathrm{Vc}$ is the peak to peak ripple voltage of the capacitor.

Table 6. Buck Converter parameter values as used in our simulation

\begin{tabular}{|c|l|}
\hline Parameter & Value \\
\hline$V_{\text {in }}$ & $625 \mathrm{~V}$ \\
\hline$V_{\text {out }}$ & $400 \mathrm{~V}$ \\
\hline$L$ & $10 \mu \mathrm{H}$ \\
\hline$C$ & $100 \mu \mathrm{F}$ \\
\hline$f_{s}$ & $20 \mathrm{KHz}$ \\
\hline
\end{tabular}

\subsection{The Battery Charge Controller}

The battery charge controller consists of voltage control, current control, and charger code to achieve CCCV FAST CHARGING of the battery. The entire charging process is divided into two modes, first one is constant current mode and second one is constant voltage mode. 


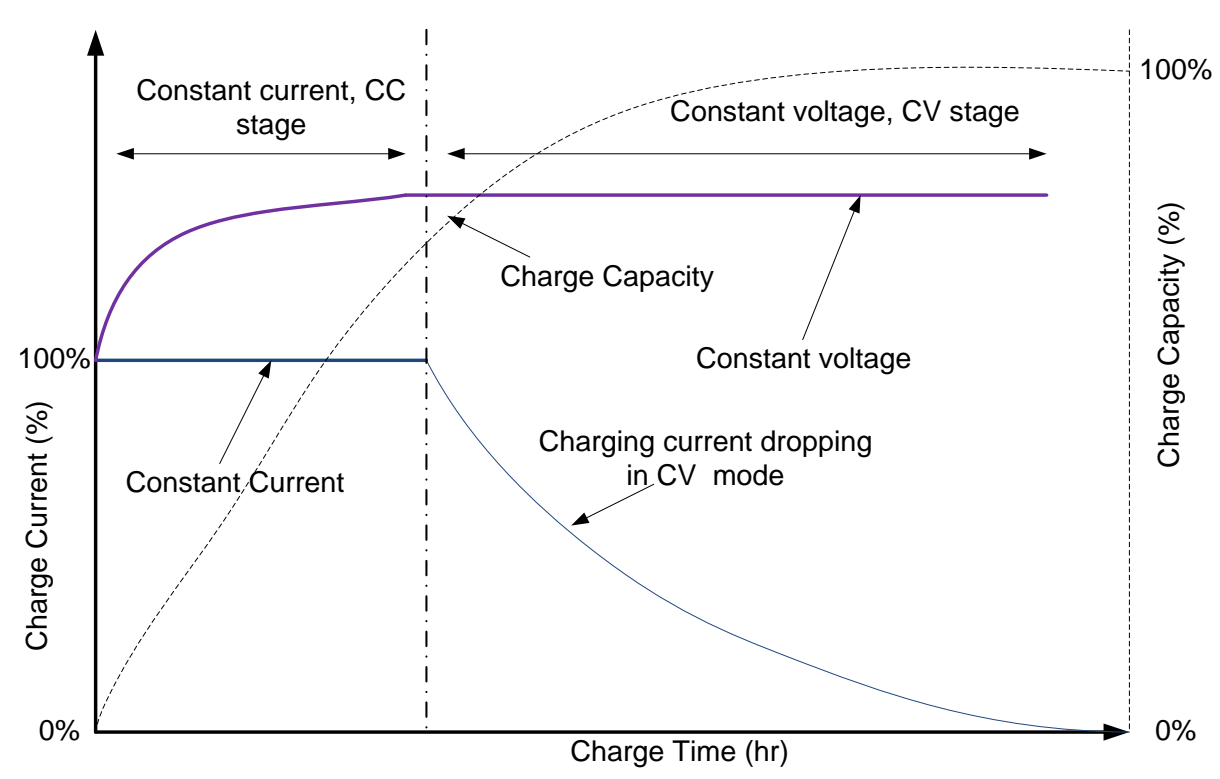

Figure 28. CCCV Battery Charging Profile

As demonstrated in figure 28 [79], constant current mode is the initial state of the charging. In this mode the battery is charged with a huge but fixed current usually referred as bulk current. This process of constant current charging will continue until the Open Circuit Voltage (OCV) of the battery is reached. The constant current mode would energize the battery to about $80 \%$ charged [80], [81]. Once the OCV of the battery is reached, the controller switches to the constant voltage mode. During this process, a constant voltage which is usually the battery OCV is maintained across the battery and the charging current drops until it reaches a preset value called float value. If the current decreases beyond the float value threshold, the charging process is terminated and the battery is considered fully charged.

In the simulation of this system however, we charge the remaining $20 \%$ of the battery indefinitely at the constant voltage stage because the battery can be considered fully charged upon the completion of the CC-CV protocol [80]. 


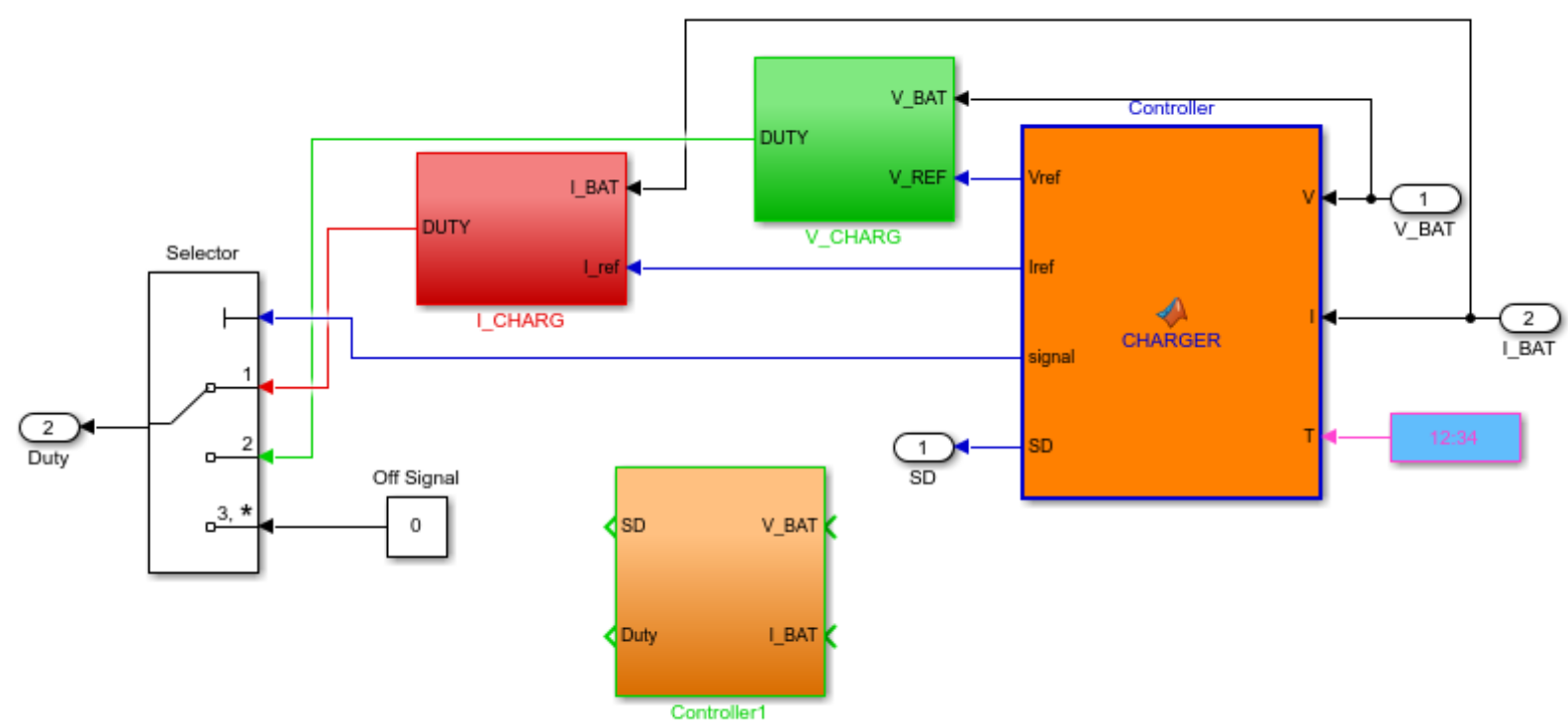

Figure 29. Battery Charge Controller

The battery charge controller in fig. 19 charges the battery with $125 \mathrm{~A}$ in the bulk mode and then charges the battery with constant voltage of $400 \mathrm{~V}$ in the absorption stage (constant voltage stage). For the simulation we used $360 \mathrm{~V}$ nominal and $56.3 \mathrm{Ah}$ for a Li-ion battery.

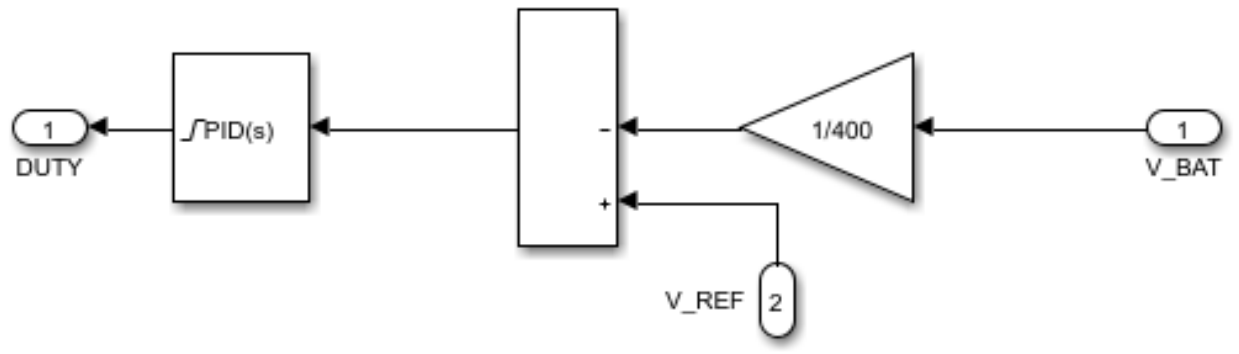

Figure 30. Voltage Controller

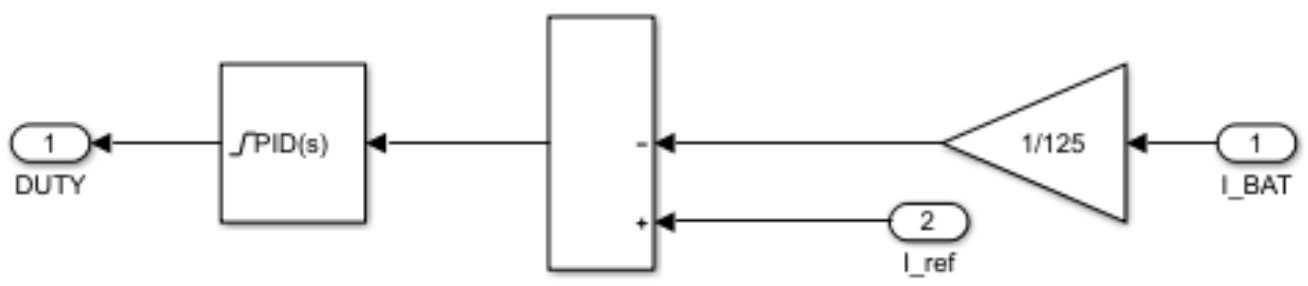

Figure 31. Current Controller 
$4^{\text {th }}$ International Conference on Modern Research in Science, Engineering and Technology

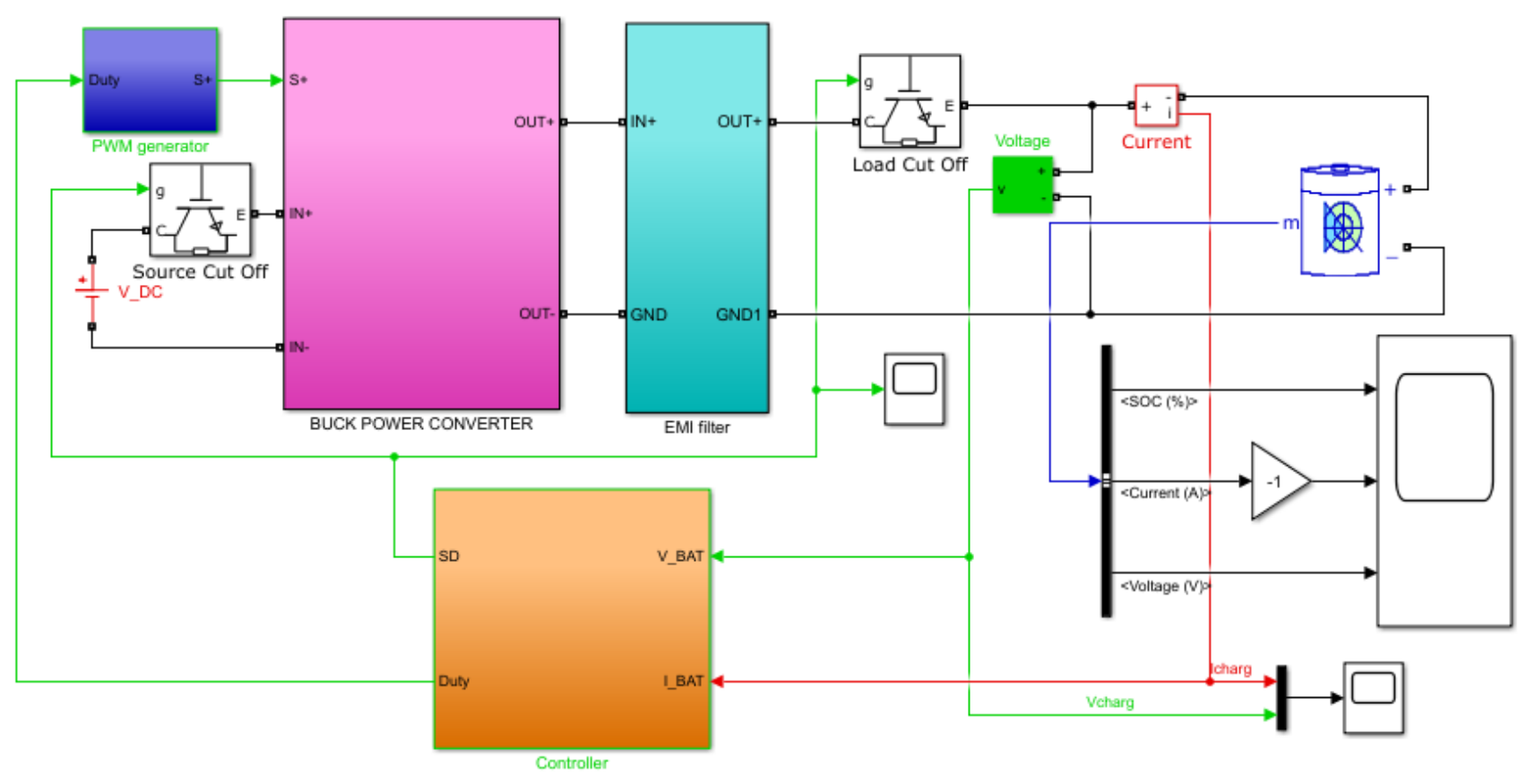

Figure 32. Buck and the Battery Charge Controller

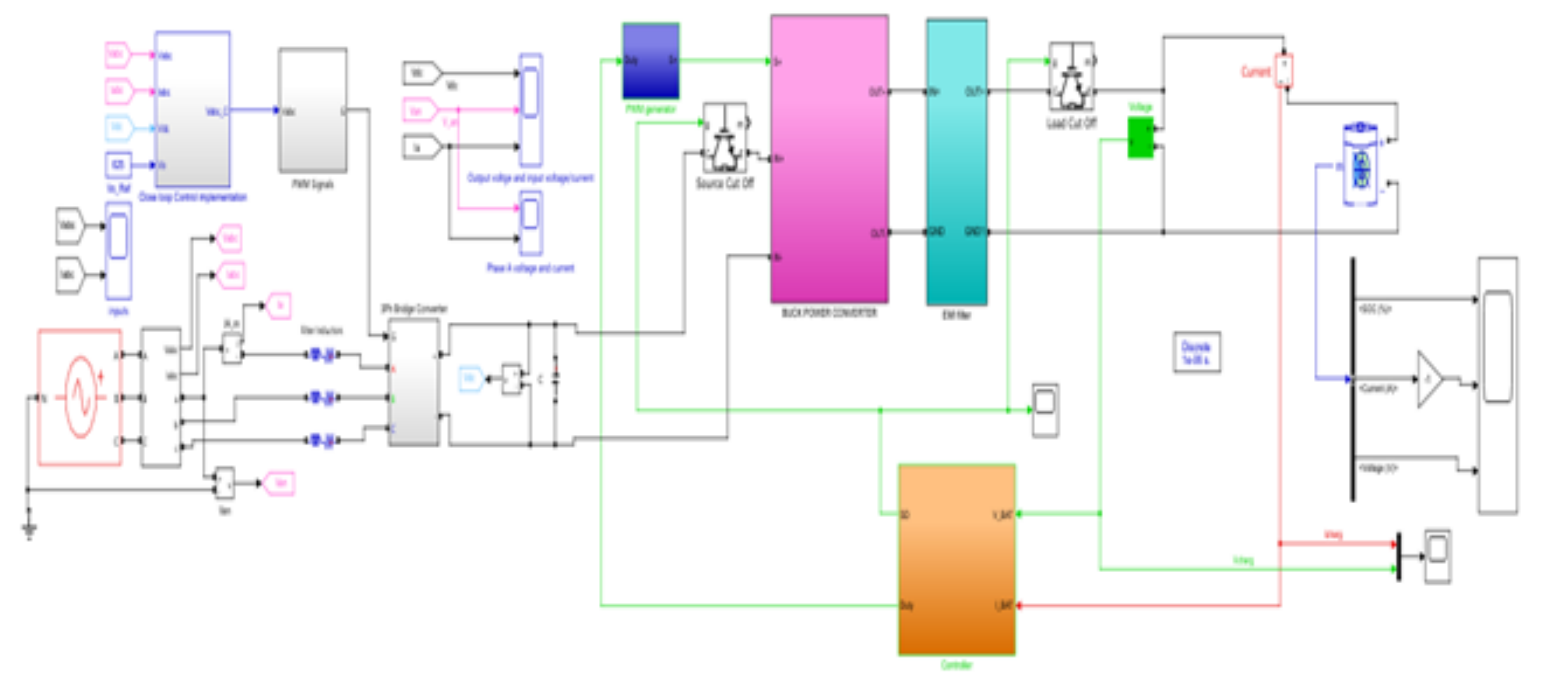

Figure 33. Full CCCV Battery Charging Simulink System 

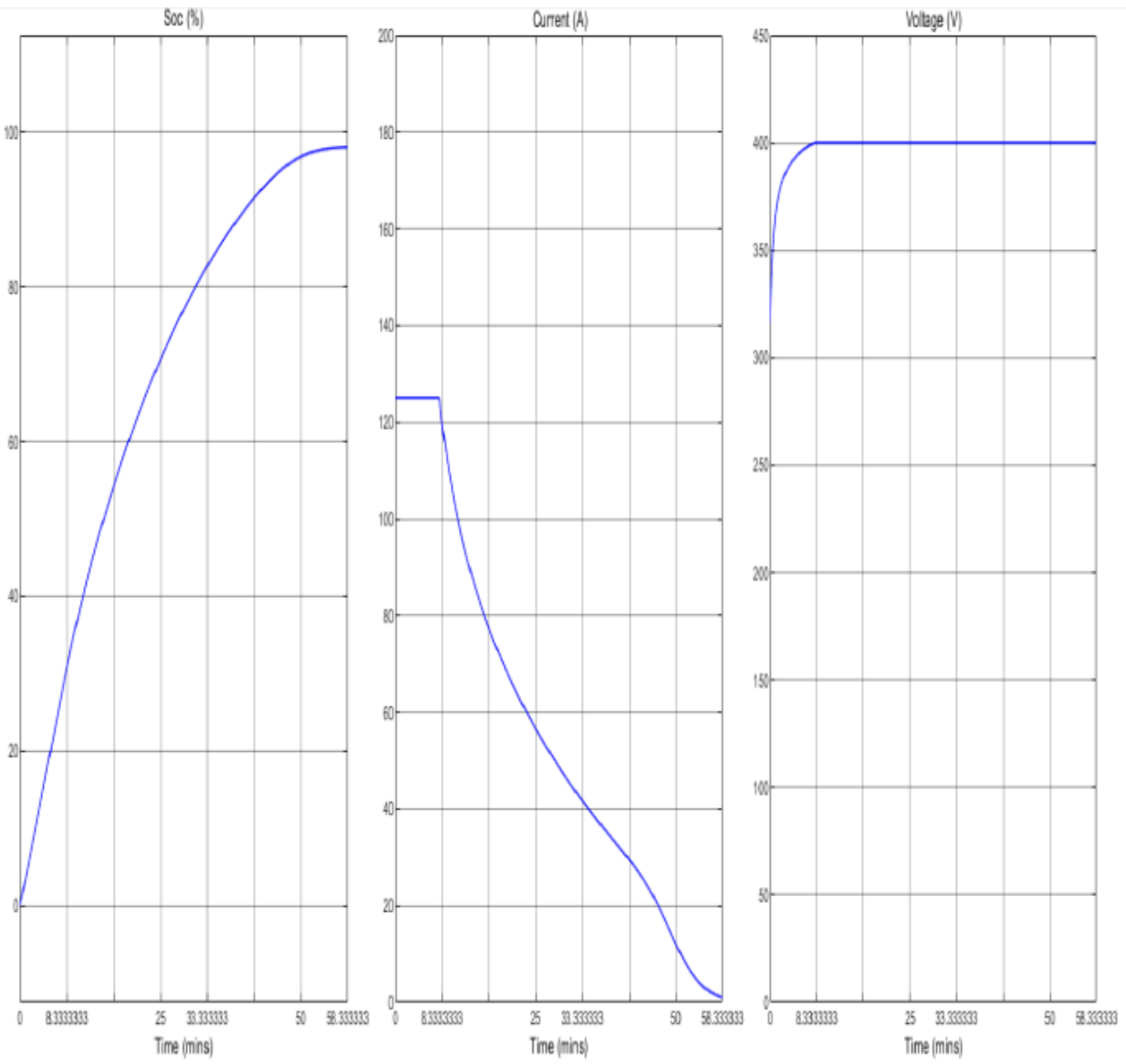

Figure 34. Simulation Results

\section{Discussion on Simulation Results}

As seen in fig. 34 the battery began charging with bulk current of $125 \mathrm{~A}$ until the OCV of the battery is reached ( $400 \mathrm{~V}$ as selected) then the charge enters the constant voltage mode until the current falls to nearly zero ampere.

\section{Hardware Implementation of the CCCV Charger Prototype}

This section explains how we built CCCV charge controller that could achieve fast charging for a $12 \mathrm{~V}$ lead-acid battery. The controller also activates or deactivates load with a relay, prints on screen the voltage, current, and power values [82]. 
$4^{\text {th }}$ International Conference on Modern Research in

Science, Engineering and Technology

5-7 MARCH 2021

BERLIN, GERMANY

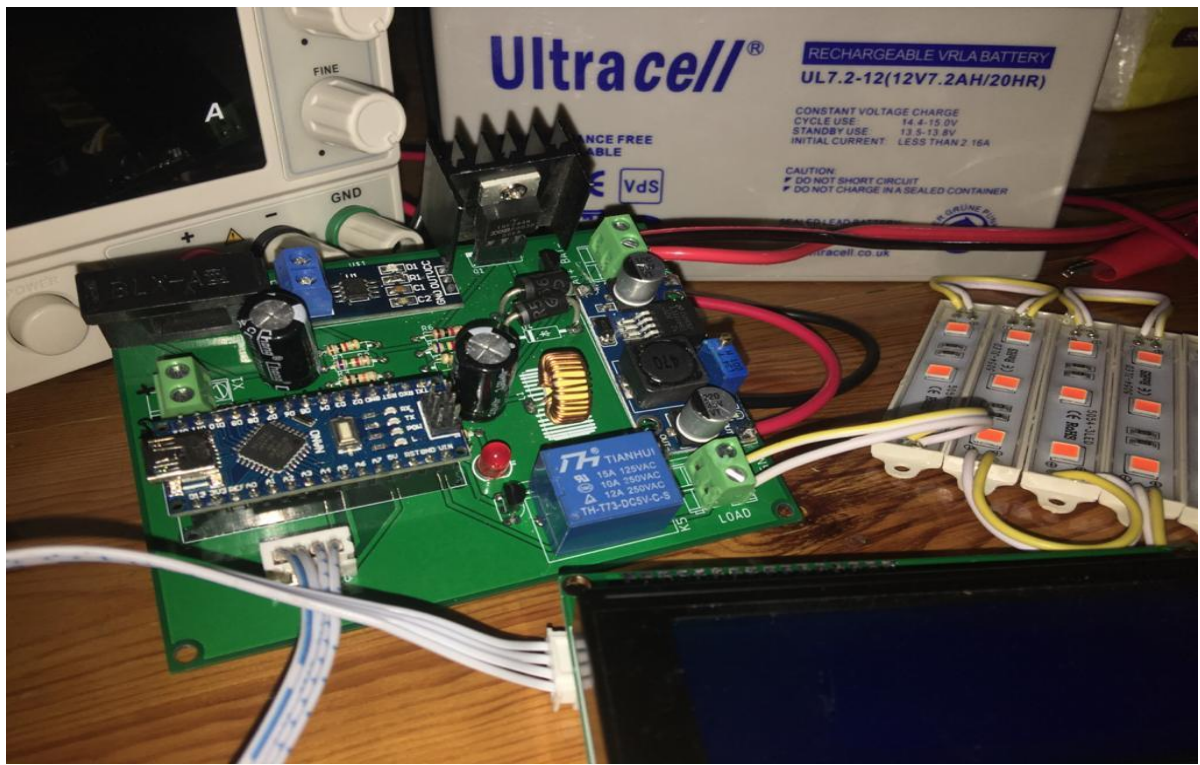

Figure 35. CCCV Battery Charger Prototype

The controller began charging the battery with a bulk constant charging current of $2 \mathrm{~A}$ until $14.4 \mathrm{~V}$ is reached which is the battery's OCV. Then the controller changes to charging the battery with a constant voltage of $14.4 \mathrm{~V}$ indefinitely at a very low current flow. The controller is supplied from a power supply however ac-dc rectifier or solar panels can be used.

\subsection{Parts and Schematic of the Charge Controller}

Arduino microcontroller is used to read input and output voltage, current values, and process the calculations. A variable buck converter circuit that will be able to regulate the output voltage and keep it constant is made and controlled with a PWM signal from the Arduino. Current sensor ACS712 module is used in order to read and limit the current value. A relay is used to enable or disable the load. A 20 by 4 i2c connected Liquid Crystal Display; LCD is used to print the values. The Arduino is supplied from a fixed value small 2amps buck converter set to $5 \mathrm{~V}$. 
$4^{\text {th }}$ International Conference on Modern Research in Science, Engineering and Technology

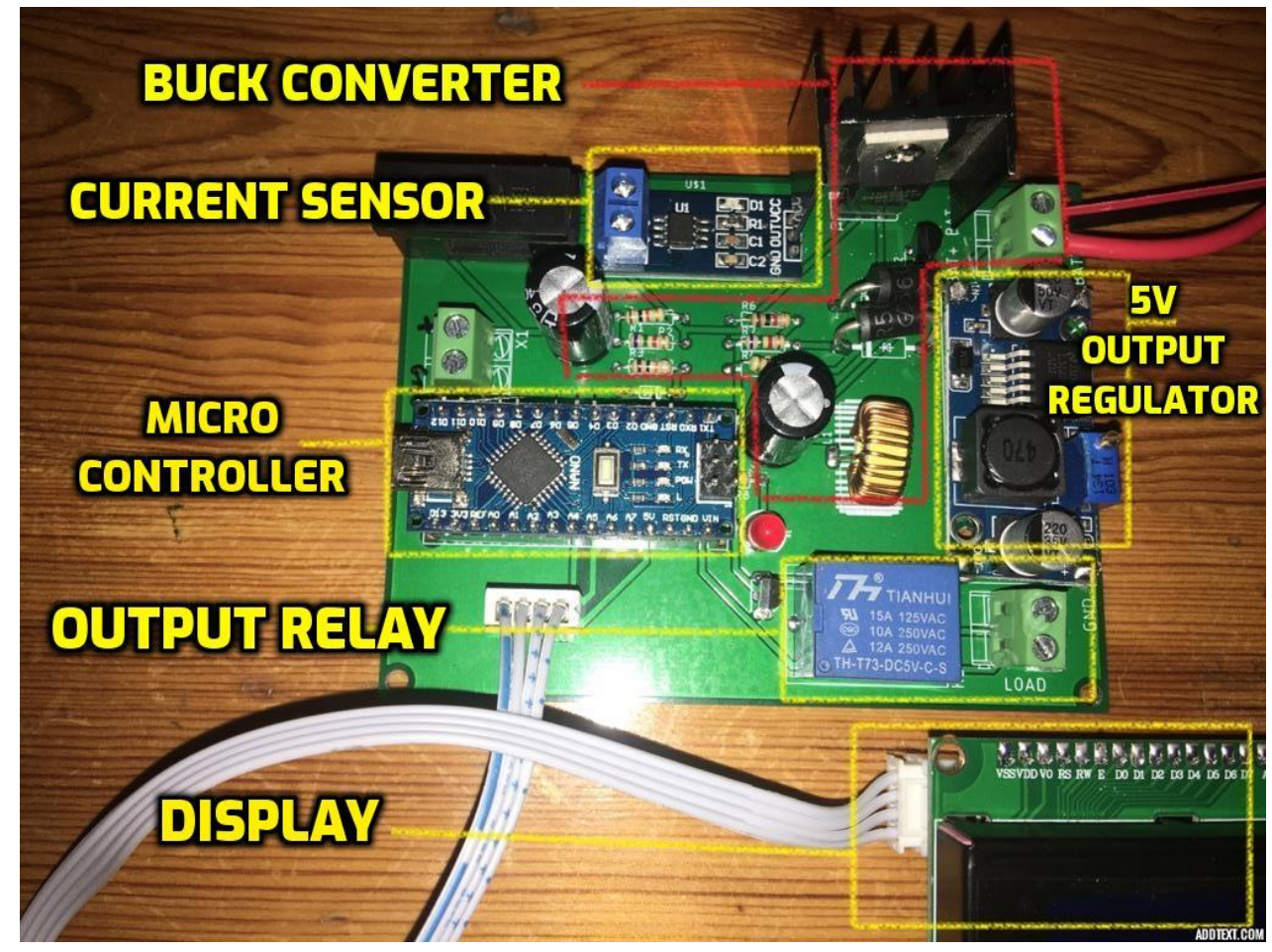

Figure 36. Parts of the charge controller
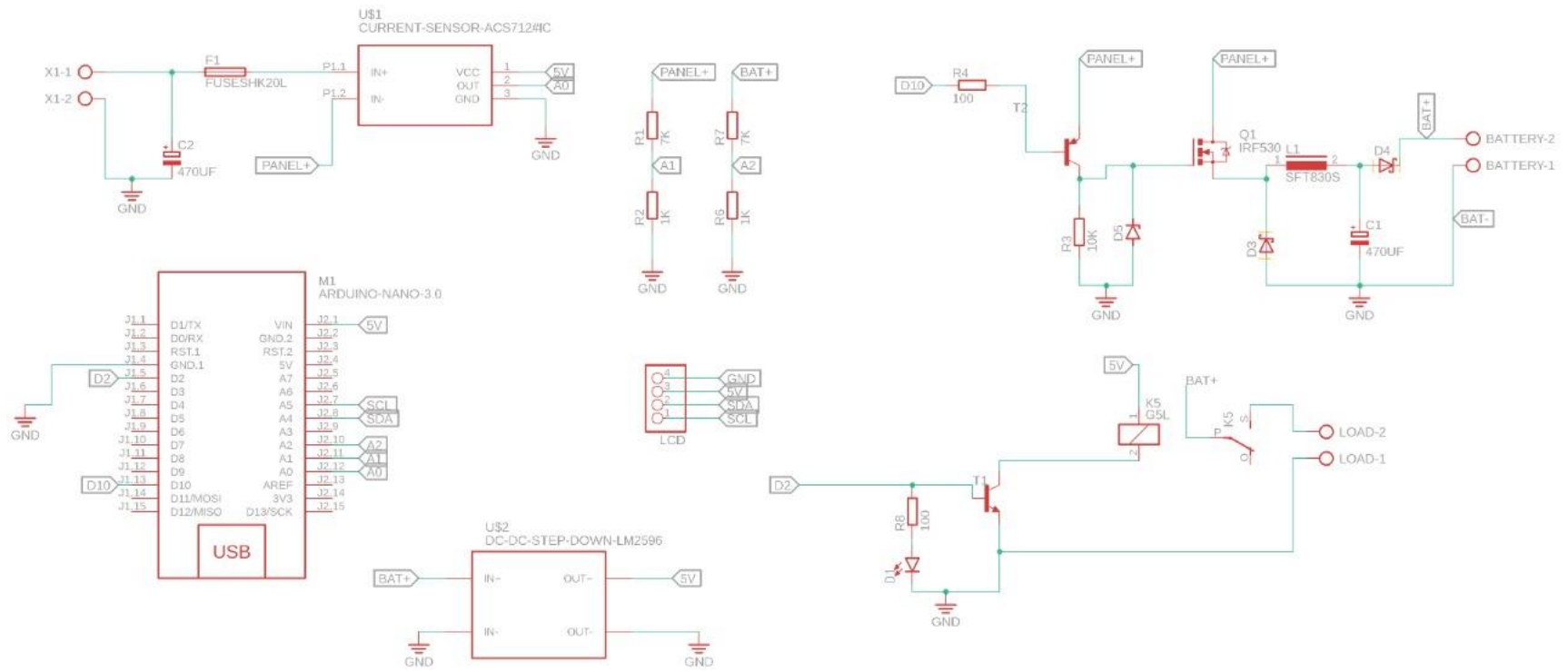

Figure 37. Schematic of the Charge Controller 
$4^{\text {th }}$ International Conference on Modern Research in Science, Engineering and Technology
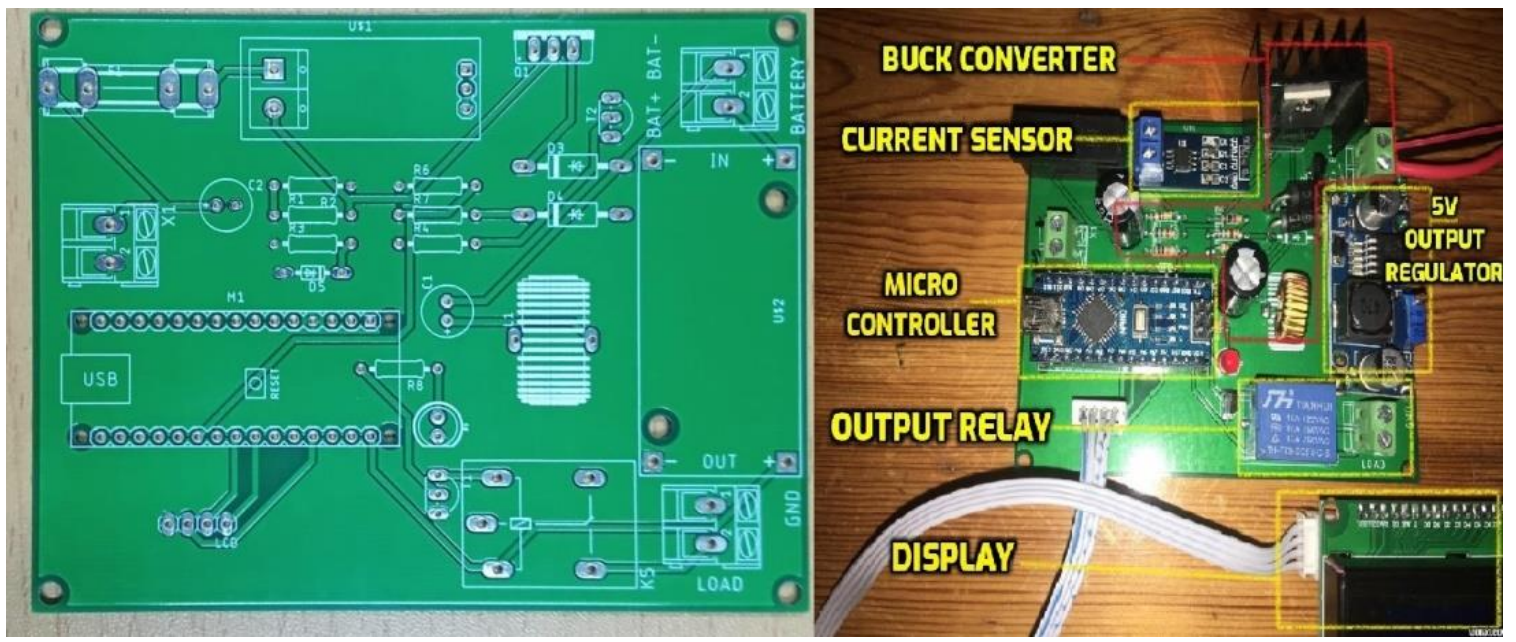

Figure 38. The Prototype PCB of the Charge Controller

\subsection{Results and Discussions on the Implemented Prototype}

The code for the CCCV control is uploaded to the Arduino and the charger began charging the battery in bulk mode with current equals to $2 \mathrm{~A}$.

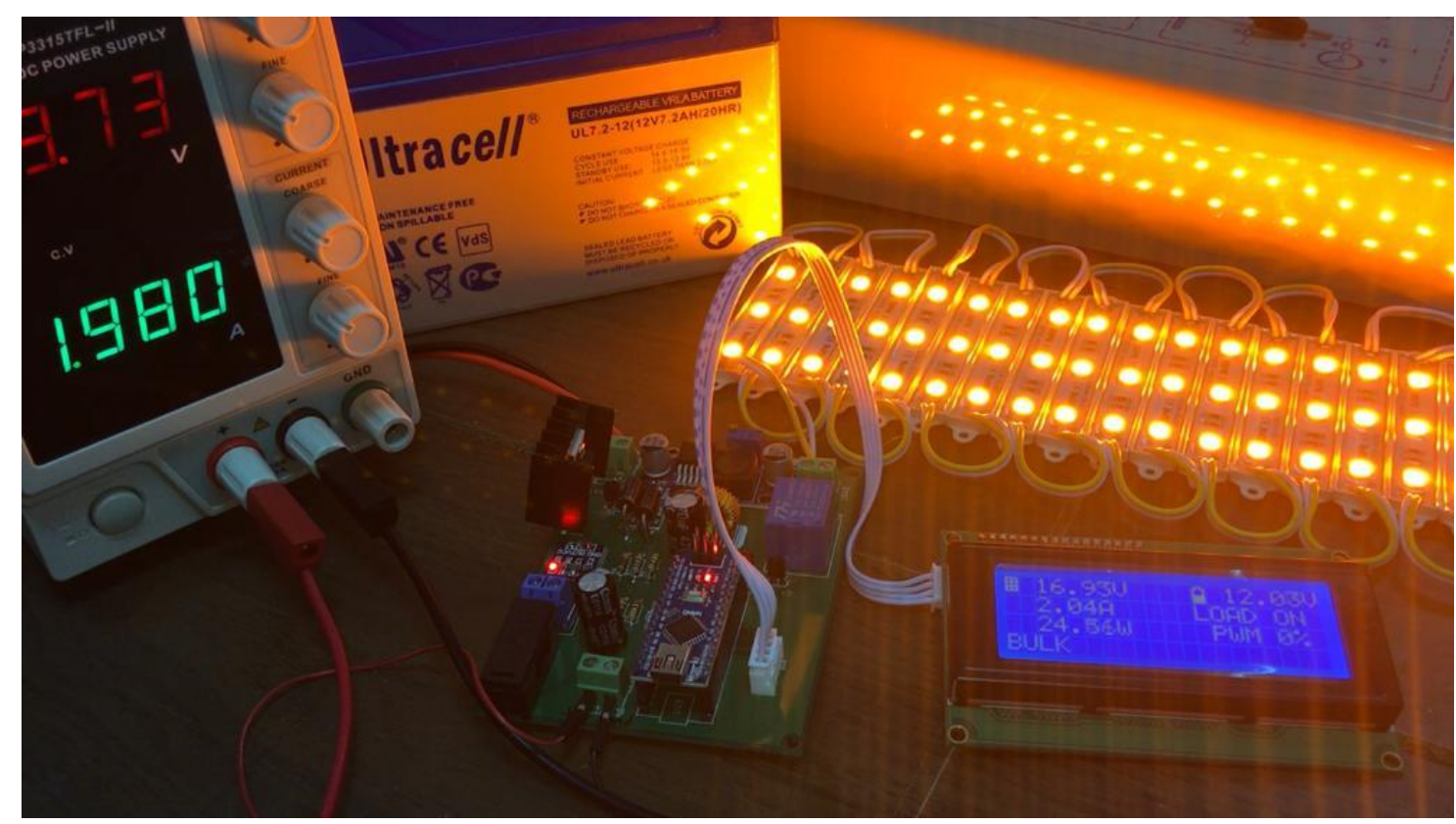

Figure 39. Constant Current Charging (Bulk Mode)

After reaching $14.7 \mathrm{~V}$ the charger switches to charging the battery in Constant Voltage Mode (absorption stage). 


\section{$4^{\text {th }}$ International Conference on Modern Research in Science, Engineering and Technology}

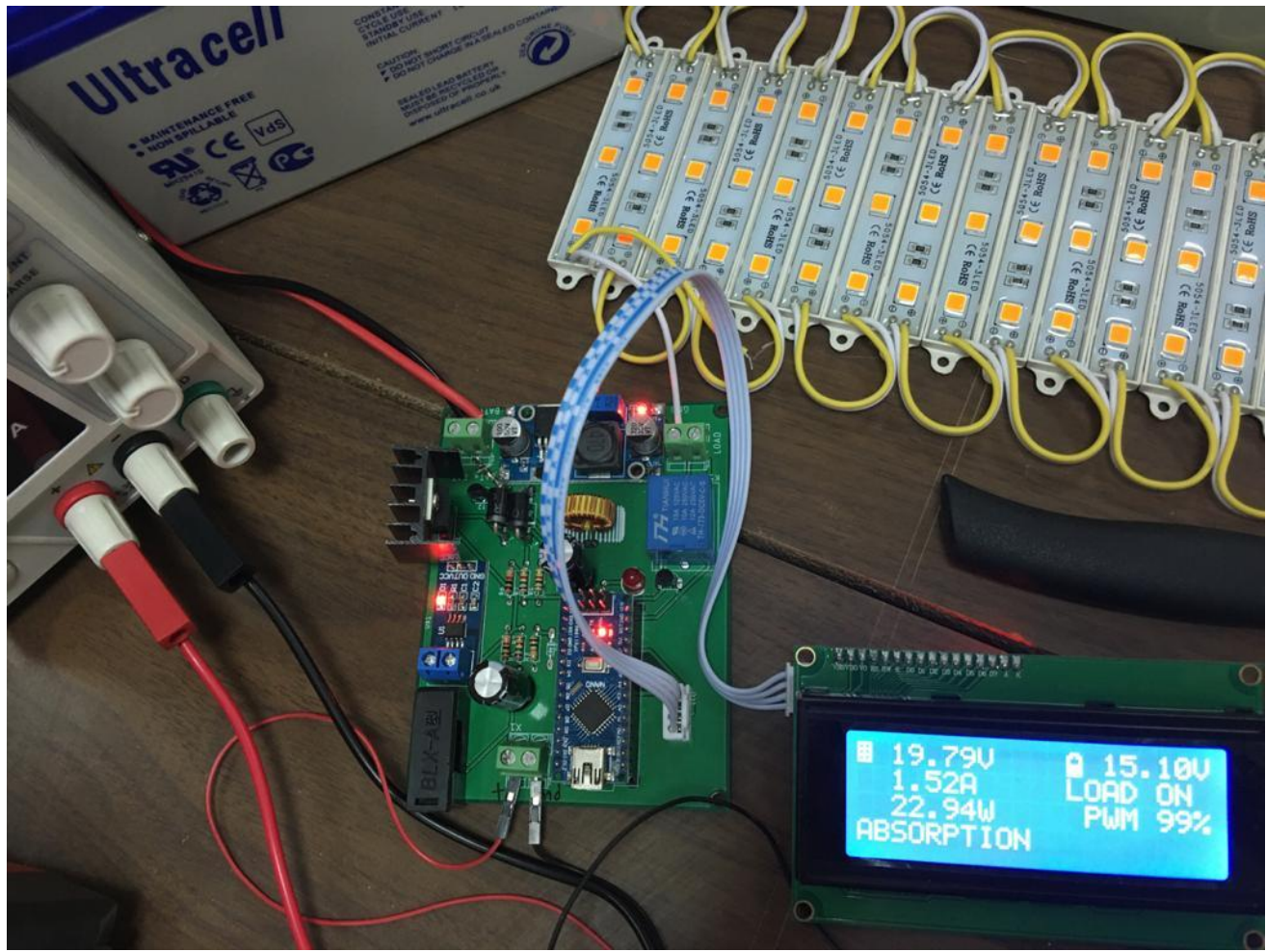

Figure 40. Constant Voltage Charging

\section{Conclusion}

This article detailed the development of fast charging technologies to serve the end user focusing on designing a buck-type dc fast charger prototype for EVs. The motivation that led to the approach of this topic is presented in the introductory part, with emphasis on the extreme phenomena resulting from global warming, with direct involvement of the factors that lead to the burning and consumption of fossil fuels.

The limitations and disadvantages of the existing methods were discussed and the design and development of a closed-loop DC-DC buck converter based battery charger for charging a PEV using the constant-current and constant-voltage (CCCV) charging scheme is proposed.

The proposed charger mainly consists of three parts: Three-phase Rectifier, DC-DC converter and Battery system. The second chapter is dedicated to the Three-phase Con-trolled Rectifier, starting with topologies, deepening the mathematical model, adopting the Voltage Oriented Control (VOC) strategy to control the three phase rectifier based on high performance direct-quadrature- coordinate controllers, ending with overall rectifier simulation, using MatLAB Simulink. The third chapter actually presents the simulation part, with emphasis on the related diagrams, presentation of parameters, highlighting the battery charge controller for CCCV charging and presentation of the final results. The final part is dedicated to the practical application itself, where a Lead-acid battery is used in the prototype testing. However, lithium-ion battery is normally used due to its high performance.

A prototype of the CCCV charger is designed using a Power Supply, DC-DC con-verter, Arduino NANO, Current Sensor and Buck Module, to validate the results ex-perimentally. 
$4^{\text {th }}$ International Conference on Modern Research in

Science, Engineering and Technology

5-7 MARCH 2021

BERLIN, GERMANY

Conflicts of Interest: The authors declare no conflict of interest.

\section{References}

[1] NASA, Responding to Climate Change. [Online]. Available: https://climate.nasa.gov/solutions/adaptation-mitigation/.

[2] U. N. I. Panel, "Mitigation of Climate Change," 2014.

[3] D. Hall and N. Lutsey, "Effects of battery manufacturing on electric vehicle life-cycle greenhouse gas emissions," no. February, 2018.

[4] M. Yilmaz and P. T. Krein, "Overview Introduction Charger Power Levels Unidirectional and Bidirectional Chargers Integrated Chargers Conductive and Inductive Charging Conclusion," 2012 IEEE Int. Electr. Veh. Conf. IEVC 2012, pp. 1$33,2012$.

[5] and C. C. H. Feng, T. Cai, S. Duan, J. Zhao, X. Zhang, "An lcc-compensated resonant converter optimized for robust reaction to large coupling variation in dynamic wireless power transfer," IEEE Trans. Ind. Electron., vol. 63, n, pp. 6591-6601.

[6] F. M. and W. Eberle, "Overview of wireless power transfer technologies for electric vehicle battery charging," IET Power Electron., vol. 7, no. 1, pp. 60-66.

[7] P. T. D. Patil, M. K. McDonough, J. M. Miller, B. Fahimi and Balsara, "Wireless power transfer for vehicular applications: Overview and challenges," IEEE Trans. Transp. Electrif., vol. 4, no. 1, pp. 3-37.

[8] A. Khaligh, S. Member, S. Dusmez, and S. Member, "Comprehensive Topological Analysis of Conductive and Inductive Charging Solutions for Plug-In Electric Vehicles," vol. 61, no. 8, pp. 3475-3489, 2012.

[9] M. Y. and P. T. Krein, "Review of battery charger topologies, charging power levels, and infrastructure for plug-in electric and hybrid vehicles," IEEE Trans. Power Electron., vol. 28, no. 5, p. May 2013.

[10] E. Loveday, "Rare look inside tesla supercharger." https://insideevs.com/news/322486/rare-look-inside-tesla-supercharger/.

[11] A. B. Singh, B. N. Singh, A. Chandra, K. Al-Haddad, A. Pandey and D. P. Kothari, "A review of three-phase improved power quality acdc converters," IEEE Trans. Ind. Electron., vol. 51, no. 3, pp. 641-660.

[12] J. W. K. and T. Friedli, "The essence of three-phase pfc rectifier systems-part i," IEEE Trans. Power Electron., vol. 28, no. 1, pp. 176-198.

[13] N. B. D. Aggeler, F. Canales, H. Zelaya-De La Parra, A. Coccia and and O. Apeldoorn, "Ultra-fast dc-charge infrastructures for ev-mobility and future smart 


\section{$4^{\text {th }}$ International Conference on Modern Research in Science, Engineering and Technology}

5-7 MARCH 2021

BERLIN, GERMANY

grids," 2010 IEEE PES Innov. Smart Grid Technol. Conf. Eur. (ISGT Eur., pp. 1-8.

[14] and D. K. T. Kang, C. Kim, Y. Suh, H. Park, B. Kang, "A design and control of bidirectional non-isolated dc-dc converter for rapid electric vehicle charging system," in in 2012 Twenty-Seventh Annual IEEE Applied Power Electronics Conference and Exposition (APEC), pp. 14-21.

[15] N. C. and D. Boroyevich, "A comprehensive study of neutralpoint voltage balancing problem in three-level neutral-point-clamped voltage source pwm inverters," IEEE Trans. Power Electron., vol. 15, no. 2, pp. 242-249.

[16] and J. W. S. Rivera, B.Wu, S. Kouro, V. Yaramasu, "Electric vehicle charging station using a neutral point clamped converter with bipolar dc bus," IEEE Trans. Ind. Electron., vol. 62, no. 4, pp. 1999-2009.

[17] and X. G. L. Tan, B. Wu, V. Yaramasu, S. Rivera, "Effective voltage balance control for bipolar-dc-bus-fed ev charging station with threelevel dc-dc fast charger," IEEE Trans. Ind. Electron., vol. 63, no. 7, pp. 4031-4041.

[18] C. W. J. Kim, J. Lee, T. Eom, K. Bae, M. Shin, "Design and control method of 25kw high efficient ev fast charger," in 21st International Conference on Electrical Machines and Systems (ICEMS), pp. 2603-2607.

[19] D. M. S. Chen, W. Yu, "Design and implementation of forced air-cooled, 140khz, $20 \mathrm{kw}$ sic mosfet based vienna pfc," in IEEE Applied Power Electronics Conference and Exposition (APEC), pp. 1196-1203.

[20] A. J. A. Anderson, M. Haider, D. Bortis, J. W. Kolar, M. Kasper and G. Deboy, "New synergetic control of a $20 \mathrm{kw}$ isolated vienna rectifier front-end ev battery charger," 20th Work. Control Model. Power Electron. (COMPEL), pp. 1-8.

[21] J. W. Kolar, T. Nussbaumer, M. Baumann, "Comprehensive design of a three-phase three-switch buck-type pwm rectifier," IEEE Trans. Power Electron., vol. 22, no. 2, pp. 551-562.

[22] J. W. K. A. Stupar, T. Friedli, J. Minibock, "Towards a 99\% efficient three-phase buck-type pfc rectifier for 400-v dc distribution systems," IEEE Trans. Power Electron., vol. 27, no. 4, pp. 1732-1744.

[23] E. A. B. Guo, F. Wang, "A novel three-phase current source rectifier with delta-type input connection to reduce the device conduction loss," IEEE Trans. Power Electron., vol. 31, no. 2, pp. 1074-1084.

[24] M. S. J. Lei, S. Feng, J. Zhao, W. Chen, P. Wheeler, "An improved three-phase buck rectifier topology with reduced voltage stress on transistors," IEEE Trans. Power Electron., pp. 1-1, 2019.

[25] A. H. Y. Du, S. Lukic, B. Jacobson, "Review of high power isolated bi-directional dcdc converters for phev/ev dc charging infrastructure," IEEE Energy Convers. Congr. Expo., pp. 553-560. 


\section{$4^{\text {th }}$ International Conference on Modern Research in Science, Engineering and Technology}

5-7 MARCH 2021

BERLIN, GERMANY

[26] P. H. and A. Khaligh, "Comprehensive analyses and comparison of $1 \mathrm{kw}$ isolated dc-dc converters for bidirectional ev charging systems," IEEE Trans. Transp. Electrif., vol. 3, no. 1, pp. 147-156.

[27] F. L. J. Sabate, V. Vlatkovic, R. Ridley, "High-voltage, highpower, zvs, full-bridge pwm converter employing an active snubber," in in [Proceedings] APEC'91: Sixth Annual Applied Power Electronics Conference and Exhibition, pp. 158-163.

[28] W. G. D. D. S. Gautam, F. Musavi, W. Eberle, "A zerovoltage switching full-bridge dc-dc converter with capacitive output filter for plug-in hybrid electric vehicle battery charging," IEEE Trans. Power Electron., vol. 28, no. 12, pp. 5728-5735.

[29] A. B. M. Pahlevaninezhad, P. Das, J. Drobnik, P. K. Jain, "A novel zvzcs full-bridge dc/dc converter used for electric vehicles," IEEE Trans. Power Electron., vol. 27, no. 6, pp. 2752-2769.

[30] G. H. Bo Yang, F. C. Lee, A. J. Zhang, "Llc resonant converter for front end dc/dc conversion," in Seventeenth Annual IEEE Applied Power Electronics Conference and Exposition (Cat. No.02CH37335), pp. 1108-1112.

[31] J. W. K. J. E. Huber, J. Miniböck, "Generic derivation of dynamic model for half-cycle dcm series resonant converters," IEEE Trans. Power Electron., vol. 33, no. 1, pp. 4-7.

[32] P. J. M. Pahlevani, S. Pan, "A hybrid phase-shift modulation technique for dc/dc converters with a wide range of operating conditions," IEEE Trans. Ind. Electron., vol. 63, no. 12 , pp. $7498-7510$.

[33] A. K. H. Wang, S. Dusmez, "Maximum efficiency point tracking technique for llcbased pev chargers through variable dc link control," IEEE Trans. Ind. Electron., vol. 61, no. 11, pp. 6041-6049.

[34] Y. L. Z. Hu, Y. Qiu, L. Wang, "An interleaved llc resonant converter operating at constant switching frequency," IEEE Trans. Power Electron., vol. 29, no. 6, pp. 29312943.

[35] E. D. M. N. Kheraluwala, R. W. Gascoigne, D. M. Divan and Baumann, "Performance characterization of a high-power dual active bridge dc-to-dc converter," IEEE Trans. Ind. Appl., vol. 28, no. 6, pp. 1294-1301.

[36] M. H. K. R. W. De Doncker, D. M. Divan, "A threephase soft-switched high power density dc/dc converter for high power applications," in IEEE Industry Applications Society Annual Meeting, pp. 796-805.

[37] B. S. H. Wen, W. Xiao, "Nonactive power loss minimization in a bidirectional isolated dc-dc converter for distributed power systems," IEEE Trans. Ind. Electron., vol. 61, no. 12 , pp. 6822-6831.

[38] A. A. Rodríguez, A. Vázquez, D. G. Lamar, M. M. Hernando and J. Sebastián, "Different purpose design strategies and techniques to improve the performance of a dual active bridge with phase-shift control," IEEE Trans. Power Electron., vol. 30, no. 


\section{$4^{\text {th }}$ International Conference on Modern Research in Science, Engineering and Technology}

2, pp. $790-804$.

[39] W. S. B. Zhao, Q. Song, W. Liu, "Current-stress-optimized switching strategy of isolated bidirectional dc-dc converter with dualphase- shift control," IEEE Trans. Ind. Electron., vol. 60, no. 10, pp. 4458-4467.

[40] A. R. O. G. Oggier, G. O. García, "Modulation strategy to operate the dual active bridge dc-dc converter under soft switching in the whole operating range," IEEE Trans. Power Electron., vol. 26, no. 4, pp. 1228-1236.

[41] F. K. and J. W. Kolar, "Efficiency-optimized high-current dual active bridge converter for automotive applications," IEEE Trans. Ind. Electron., vol. 59, no. 7, pp. 27452760 .

[42] P. S. J. Hiltunen, V. Väisänen, R. Juntunen, "Variablefrequency phase shift modulation of a dual active bridge converter," IEEE Trans. Power Electron., vol. 30, no. 12, pp. $7138-7148$.

[43] M. M. A. Taylor, G. Liu, H. Bai, A. Brown, P. M. Johnson, "Multiple-phase-shift control for a dual active bridge to secure zero-voltage switching and enhance light-load performance," IEEE Trans. Power Electron., vol. 33, no. 6, pp. 4584-4588.

[44] D. D. L. Xue, Z. Shen, D. Boroyevich, P. Mattavelli, "Dual active bridge-based battery charger for plug-in hybrid electric vehicle with charging current containing low frequency ripple," IEEE Trans. Power Electron., vol. 30, no. 12, pp. 7299-7307.

[45] Z. L. W. Chen, P. Rong, "Snubberless bidirectional dc-dc converter with new cllc resonant tank featuring minimized switching loss," IEEE Trans. Ind. Electron., vol. 57, no. 9, pp. 3075- 3086 .

[46] J. L. C. Wang, S. Zhang, Y. Wang, B. Chen, "A 5-kw isolated high voltage conversion ratio bidirectional cltc resonant dc-dc converter with wide gain range and high efficiency," IEEE Trans. Power Electron., vol. 34, no. 1, pp. 340-355.

[47] J. X. J. Huang, X. Zhang, Z. Shuai, X. Zhang, P. Wang, L. H. Koh and and X. Tong, "Robust circuit parameters design for the cllc-type dc transformer in the hybrid ac-dc microgrid," IEEE Trans. Ind. Electron., vol. 66, no. 3, pp. 1906-1918.

[48] P. H. and A. Khaligh, "Design of $1 \mathrm{kw}$ bidirectional half-bridge cllc converter for electric vehicle charging systems," in IEEE International Conference on Power Electronics, Drives and Energy Systems (PEDES), pp. 1-6.

[49] X. G. C. Zhang, P. Li, Z. Kan, X. Chai, "Integrated halfbridge cllc bidirectional converter for energy storage systems," IEEE Trans. Ind. Electron., vol. 65, no. 5, pp. 3879-3889.

[50] J. S. L. F. Z. Peng, Hui Li, Gui-Jia Su, "A new zvs bidirectional dc-dc converter for fuel cell and battery application," IEEE Trans. Power Electron., vol. 19, no. 1, pp. 5465 . 


\section{$4^{\text {th }}$ International Conference on Modern Research in Science, Engineering and Technology}

5-7 MARCH 2021

BERLIN, GERMANY

[51] G.-J. S. Hui Li, Danwei Liu, F. Z. Peng, "Small signal analysis of a dual half bridge isolated zvs bi-directional dc-dc converter for electrical vehicle applications," in IEEE 36th Power Electronics Specialists Conference, pp. 2777-2782.

[52] A. C. O. Garcia, P. Zumel, A. de Castro, "Automotive dc-dc bidirectional converter made with many interleaved buck stages," IEEE Trans. Power Electron., vol. 21, no. 3, pp. 578-586.

[53] W. Y. J. Zhang, J. Lai, R. Kim, "High-power density design of a soft-switching highpower bidirectional dc-dc converter," IEEE Trans. Power Electron., vol. 22, no. 4, pp. $1145-1153$.

[54] J. B. D. Christen, F. Jauch, "Ultra-fast charging station for electric vehicles with integrated split grid storage," in 17th European Conference on Power Electronics and Applications (EPE'15 ECCE-Europe), pp. 1-11.

[55] M. M. J. M. T. Zhang, Yimin Jiang, F. C. Lee, "Singlephase three-level boost power factor correction converter," in IEEE Applied Power Electronics Conference and Exposition - APEC'95, pp. 434-439.

[56] P. B. P. J. Grbovic, P. Delarue, P. Le Moigne, "A bidirectional three-level dc-dc converter for the ultracapacitor applications," IEEE Trans. Ind. Electron., vol. 57, no. 10 , pp. 3415-3430.

[57] A. K. S. Dusmez, A. Hasanzadeh, "Comparative analysis of bidirectional three-level dc-dc converter for automotive applications," IEEE Trans. Ind. Electron., vol. 62, no. 5, pp. 3305-3315.

[58] B. S. R. M. Cuzner, A. R. Bendre, P. J. Faill, "Implementation of a non-isolated three level dc/dc converter suitable for high power systems," IEEE Ind. Appl. Annu. Meet., pp. 2001-2008.

[59] B. W. L. Tan, N. Zhu, "An integrated inductor for eliminating circulating current of parallel three-level dc-dc converter-based ev fast charger," IEEE Trans. Ind. Electron., vol. 63 , no. 3, pp. 1362-1371.

[60] S. L. S. Bai, D. Yu, "Optimum design of an ev/phev charging station with dc bus and storage system," in IEEE Energy Conversion Congress and Exposition, pp. 1178-1184.

[61] A. H. Y. Du, X. Zhou, S. Bai, S. Lukic, "Review of nonisolated bi-directional dc-dc converters for plug-in hybrid electric vehicle charge station application at municipal parking decks," in Twenty-Fifth Annual IEEE Applied Power Electronics Conference and Exposition (APEC), pp. 1145-1151.

[62] V. Y. L. Tan, B. Wu, S. Rivera, "Comprehensive dc power balance management in high-power three-level dc-dc converter for electric vehicle fast charging," IEEE Trans. Power Electron., vol. 31, no. 1, pp. 89-100.

[63] H. H. Z. Zhang, H. Tu, X. She, T. Sadilek, R. Ramabhadran and and W. Earls, "Highefficiency silicon carbide (sic) converter using paralleled discrete devices in energy 


\section{$4^{\text {th }}$ International Conference on Modern Research in Science, Engineering and Technology}

5-7 MARCH 2021

BERLIN, GERMANY

storage systems," IEEE Energy Convers. Congr. Expo. (ECCE), pp. 2471-2477.

[64] L. M. T. W. Qian, H. Cha, F. Z. Peng, "55-kw variable 3x dcdc converter for plug-in hybrid electric vehicles," IEEE Trans. Power Electron., vol. 27, no. 4, pp. 1668-1678.

[65] W. P. R. Ned Mohan, Tore M. Undeland, Power Electronics: Converters, Applications, and Design, 3rd Edition, 3rd ed. New York, 2002.

[66] J. W. K. T. Nussbaumer, "Comparison of 3-phase wide output voltage Range PWM rectifiers," IEEE Trans. Ind. Electron., vol. 54, pp. 3422-3425, 2007.

[67] B. K. Bose, "Power Electronics and Motor Drives Recent Progress and Perspective," IEEE Trans. Ind. Electron., vol. 56, pp. 581-588.

[68] H. R. MUHAMMAD, POWER ELECTRONICS CIRCUITS, DEVICES, AND APPLICATIONS, THIRD. PEARSON.

[69] B. X. X. Wang, Kaizheng Huang, Shijie Yan, "Simulation of Three-Phase Voltage Source PWM Rectifier Based on Direct Current Control,” vol. 5, pp. 194-198.

[70] H. A. T. S. Kwak, "Design and rating comparisons of PWM voltage source rectifiers and active power filters for AC drives with unity power factor," IEEE Trans. Power Electron., vol. 20 No. 5, pp. 1133-1142.

[71] B. B. E.P. Burgos, D. Wiechmann, "Operation of a PWM voltage source rectifier with reduced-size input filter," IEEE Conf. Ind. Appl. 2001, 36th IAS Annu. Meet., vol. 01, pp. 323-330.

[72] Z. J. A.I. Maswood, S. Wei, "Near unity input displacement factor for voltage source PWM drives," IEEE Power Eng. Soc. Winter Meet. 2001, vol. 03, pp. 1388-1392.

[73] T. A. L. D. Grahame Holmes, Pulse Width Modulation for Power Converters: Principles and Practice. New York, 2003.

[74] K. R. . KASMIERKOWSKI MARIAN P., BLAABJERG F., "Control in power electronics, selected problem". Elsevier Science, USA. 2002. 518p. ISBN: 0-12402772- 5. .

[75] H. LENNART., "“Control of Variable- Speed Drives'. Applied Signal Processing and Control, Department of Electronics, Mälardalen University, Västerås, Sweden, 2002. 194p."

[76] L. STEFAN., "Lecture slides : ENM075 Electric Drives II. Department of Energy and Environment, Chalmers University of Technology, Göteborg, Sweden. 2009.”

[77] S. A. BONGIORNO MASSIMO, "Lecture slides: ENM100 Power Electronic Solutions for Power Systems. Department of Energy and Environment, Chalmers University of Technology, Göteborg, Sweden. 2009.”

[78] M. Dinesh, "Design, Control and Simulation of Buck Converter using PID controller 
and Design , Control and Simulation of Buck Converter using PID controller and Reference Regulator Technique," no. October 2015, 2020.

[79] B.

University,

"Charging

Profile." https://batteryuniversity.com/learn/article/charging_lithium_ion_batteries.

[80] R. Zhang, B. Xia, B. Li, L. Cao, Y. Lai, and W. Zheng, "A Study on the Open Circuit Voltage and State of Charge Characterization of High Capacity Lithium-Ion Battery Under Different Temperature," 2018.

[81] M. A. Hannan et al., "State - of - the - Art and Energy Management System of Lithium - Ion Batteries in Electric Vehicle Applications : Issues and Recommendations," vol. 3536, no. c, 2018.

[82] Electronoobs, MPPT Arduino Prototype [Online]. Available: https://electronoobs.com/eng_arduino_tut133.php. 